\title{
Single-Component Organic Solar Cells with Competitive Performance
}

\author{
Yakun $\mathrm{He}^{\mathrm{a}, \mathrm{b}}$ (D) \\ Ning Li ${ }^{* a, c}$ (D) \\ Christoph J. Brabec*a,c (D) \\ ${ }^{a}$ Institute of Materials for Electronics and Energy Technology (i-MEET), Friedrich- \\ Alexander-Universität Erlangen-Nürnberg, Martensstrasse 7, 91058 Erlangen, \\ Germany \\ ${ }^{\mathrm{b}}$ Erlangen Graduate School in Advanced Optical Technologies (SAOT), Paul-Gordan- \\ Straße 6, 91052 Erlangen, Germany \\ 'Helmholtz-Institute Erlangen-Nürnberg (HI ERN), Immerwahrstraße 2, 91058 \\ Erlangen, Germany \\ ning.li@fau.de; christoph.brabec@fau.de \\ Dedicated to Prof. Peter Bäuerle on the occasion of his 65th birthday.
}

Received: 19.01.2021

Accepted after revision: 24.02.2021

DOI: 10.1055/s-0041-1727234; Art ID: om-21-0013rev

License terms: CC

(C) 2021. The Author(s). This is an open access article published by Thieme under the terms of the Creative Commons Attribution License, permitting unrestricted use, distribution, and reproduction so long as the original work is properly cited. (https:// creativecommons.org/licenses/by/4.0/)

Abstract Organic semiconductors with chemically linked donor and acceptor units can realize charge carrier generation, dissociation and transport within one molecular architecture. These covalently bonded chemical structures enable single-component organic solar cells (SCOSCs) most recently to start showing specific advantages over binary or multi-component bulk heterojunction concepts due to simplified device fabrication and a dramatically improved microstructure stability. The organic semiconductors used in SCOSCs can be divided into polymeric materials, that is, double-cable polymers, diblock copolymers as well as donor-acceptor small molecules. The nature of donor and acceptor segments, the length and flexibility of the connecting linker and the resultant nanophase separation morphology are the levers which allow optimizing the photovoltaic performance of SCOSCs. While remaining at $1-2 \%$ for over a decade, efficiencies of SCOSCs have recently witnessed significant improvement to over $6 \%$ for several materials systems and to a record efficiency of $8.4 \%$. In this minireview, we summarize the recent progress in developing SCOSCs towards high efficiency and stability, and analyze the potential directions for pushing SCOSCs to the next efficiency milestone.

Key words double-cable polymers, di-block copolymers, donoracceptor small molecules, single-component organic solar cells, photovoltaic performance, device stability

\section{Introduction}

Organic solar cells (OSCs) have received great attention due to multiple advantages such as high flexibility, feasible processing by roll-to-roll printing, semi-transparency and light weight applications. ${ }^{1-4}$ In the early years, planar heterojunction $(\mathrm{PHJ})$ concepts were favored where the pure
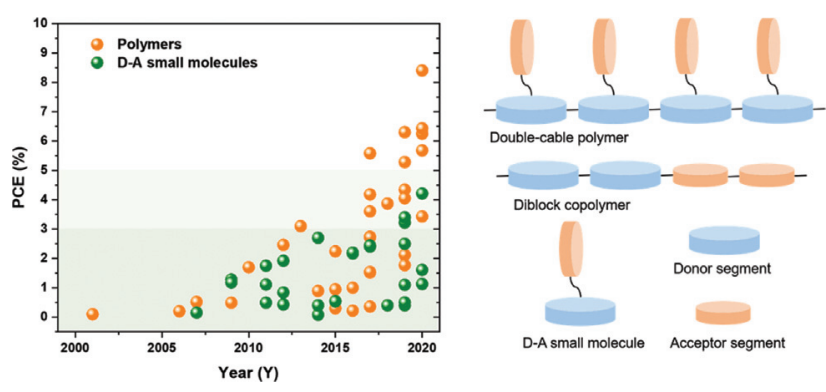

donor layer and pure acceptor layer are stacked on top of each other as a bilayer. Carrier generation and carrier separation occurred at the donor-acceptor (D-A) interface and required an energy offset as the driving force to split the excitons. ${ }^{5-10}$ However, the typically short diffusion length of excitons $(\sim 10 \mathrm{~nm})$ restricted the active layer thickness and led to incomplete light absorption. ${ }^{11}$ This problem was overcome with the bulk heterojunction $(\mathrm{BHJ})^{8}$ concept where the donor and acceptor materials are rather homogenously mixed and percolated into an interpenetrated network. ${ }^{12,13}$ With the development of new kinds of donor and acceptor materials, including push-pull semiconductors, ${ }^{14,15}$ low bandgap polymers and small molecules $^{13,16-20}$ as well as nonfullerene acceptors (NFAs), ${ }^{21-29}$ recently developed OSCs have shown efficiencies over $17 \%^{21}$ and the $20 \%$ milestone is within reach. ${ }^{30}$ When we consider the practical application of solar cells, other factors, i.e., the large-scale processing feasibility and, most importantly, stability, are of equal importance as efficiency. ${ }^{31,32}$ Highperformance $\mathrm{BHJ}$ OSCs benefit from a precisely adjustable compromise between sufficient interfaces for exciton dissociation and continuous pure domains for efficient charge transport. This requires exquisite nanostructure control by tediously optimizing multiple experimental variables, including the $\mathrm{D}: \mathrm{A}$ ratio and concentration, choice of solvents and additives, film processing methods or posttreatment methods like thermal treatment and solvent annealing., ${ }^{8,12}$ However, such carefully optimized nonequilibrium $\mathrm{BHJ}$ morphologies are frequently thermodynamically unstable, and unfavorable microstructure progression (phase segregation or intimate mixing) may occur upon external stress, such as thermal stress or illumination, resulting in microstructure-related performance losses. $^{33-35}$

One elegant strategy to address such instability issues is the development of single-component OSCs (SCOSCs) employing chemically bonded donor and acceptor blocks in one polymer or molecule by a spacer linker. ${ }^{18,36}$ This 

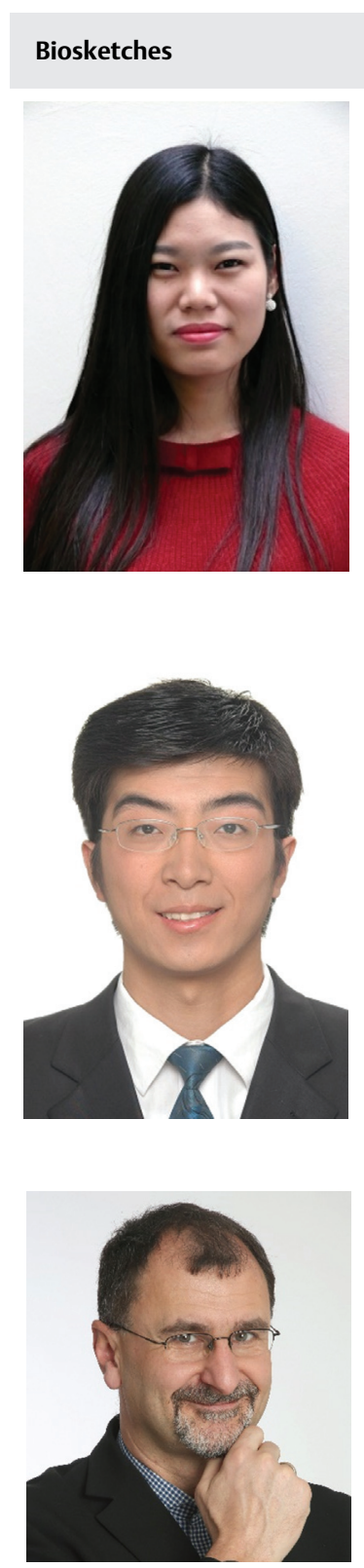

Christoph J. Brabec received his PhD (1995) in Physical Chemistry from Linz University, Austria, and joined the group of Alan Heeger at UC Santa Barbara (USA) for a sabbatical. He joined the SIEMENS research labs (project leader) in 2001, Konarka in 2004 (CTO),
Ning Li received his $\mathrm{PhD}$ degree under the supervision of Prof. Christoph J. Brabec from Friedrich-Alexander Universität ErlangenNürnberg (FAU), Germany in 2014. $\mathrm{He}$ is a research group leader at the the supervision of Prof. Christoph J. Brabec with research focus on fabrication and characterization of solution-processed organic solar cells.
Institute of Materials for Electronics and Energy Technology (i-MEET) and a visiting scientist at the Helmholtz Institute Erlangen-Nürnberg for Renewable Energy (HI-ERN) with research focus on the develop- ment and characterization of solution-processed materials and devices for photovoltaic applications, in particular on the aspects related to the industrialization of next-generation photovoltaics. linker merges the functions of light absorption, exciton dissociation and charge transport, which are otherwise performed by two different materials - donor and acceptor - into one single material. The nomenclature for this class of materials has not been fully established, and different names such as single material OSC and SCOSC were suggested for this specific call of organic semiconductors. Herein, the term "SCOSC" is used in analogy to recent reports. ${ }^{37-39}$ SCOSCs offer a simplified fabrication process and promise stabilization of the active layer morphology as well as suppression of phase separation, which is essential for scale-up. Furthermore, the fact that light absorption and charge separation would occur at the same molecule raises
Erlangen University (FAU-Professor for Material Science) in 2009, ZAE Bayern e.V. (scientific director and board member) in 2010-2020, spokesmen of the Interdisciplinary Center for Nanostructured Films (IZNF) from 2013 to 2018 and became honorary professor at the
University of Groningen (Netherlands) and director at FZ ülich (IEK-11) in 2018. His research interests include all aspects of solution processing organic, hybrid and inorganic semiconductor devices with a focus on photovoltaics and renewable energy systems. the danger of enhanced recombination. This is why SCOSCs have attracted less attention than BHJ OSCs during the last years, as fast charge recombination and inefficient charge hopping and transport resulted in low efficiency values. ${ }^{40-43}$ In SCOSCs, due to the existence of a rigid or flexible linker between the donor and the acceptor, formation of larger sized pure domains with ordered stacking actually appears, at a first superficial view, as good as impossible. Early-stage SCOSCs did not provide such continuous ambipolar charge highways, and, as a consequence, efficiencies were difficult to raise significantly beyond $1 \%{ }^{44,45}$ Readers are referred to review articles for a more detailed description on the historic SCOSC 
development. ${ }^{11,36,46-48}$ Recently, SCOSCs have taken a step addressing these microstructure limitations, which allowed closing the performance gap to the $\mathrm{BHJ}$ pendants. Today, the highest power conversion efficiency (PCE) value for SCOSC is $8.4 \%$, and the $10 \%$ milestone appears to be within reach. The aim of this mini-review is to update on the exciting progress in this promising field, manifesting that there is already sufficient experimental data evidencing superior lifetime of SCOSC, and to discuss potential directions for future improvements.

\section{Category of ScOSCs}

Actually, early-stage materials such as anthracene, merocyanine and copper phthalocyanine also belong to the active layer materials for SCOSCs. ${ }^{49-51}$ However, these materials lack the driving force for exciton dissociation and pathways for ambipolar charge transport and therefore could not exploit their full potential in solar cells. The currently developed active layer materials with covalently linked donor and acceptor moieties are based on intramolecular heterojunction concepts, and can be categorized into polymeric materials, that is, double-cable polymers and diblock copolymers as well as into D-A small molecules (Figure 1).

The typical design of a double-cable polymer embodies a polymeric donor as the backbone and molecular acceptor segments as pendent side chains. The conjugated polymer donor backbone serves naturally as a channel for hole

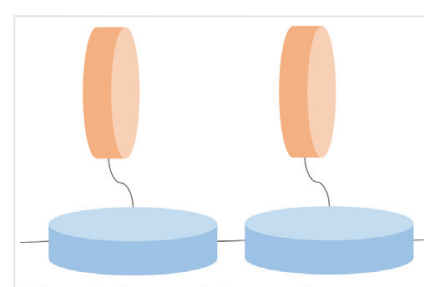

Double-cable polymer
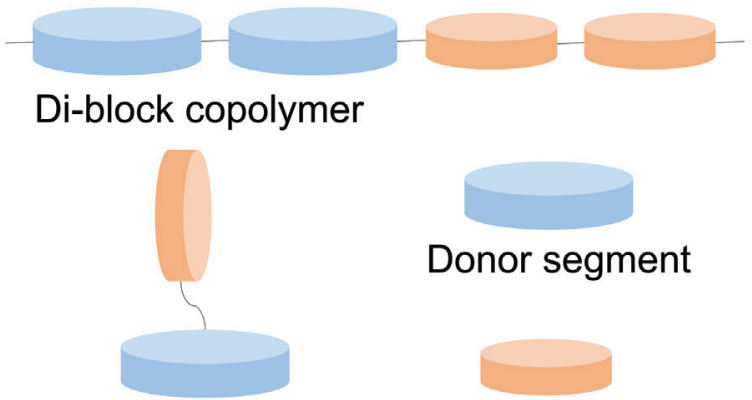

\section{D-A small molecule}

Figure 1 Schematic diagram of different material concepts for SCOSCs: double-cable polymer, di-block copolymer, D-A small molecule. transport, and the side-chain acceptor units need to aggregate and stack in order to form electron channels. The bipolar characteristics of charge transport through two separate "cables" may effectively suppress bimolecular recombination if these channels remain well separated. ${ }^{45,52-56}$ Recently reported SCOSCs with a record efficiency of $8.4 \%$ belong to the category of double-cable polymers. ${ }^{57}$ The adjustment of nanophase separation and adequate ambipolar transport channels is difficult for double-cable polymers, since both, the polymer backbone as well as the acceptor side chain, possess strong crystallinity and aggregation tendency. Therefore, the length of linker between the donor and the acceptor is key to control the interaction between these two parts.

A further category is conjugated di-block copolymers, which contain both a donor block and an acceptor block along the polymer backbone main chain. ${ }^{52}$ By planar selfassembly, ordered nanophase-separated structures with face-on chain orientation are expected to form, providing continuous charge transporting pathways. Similar to traditional block polymers, di-block copolymers can form self-assembled ordered films. ${ }^{58}$ A domain size of about $10 \mathrm{~nm}$ is considered to be an ideal film morphology for photovoltaic applications. Since di-block copolymers are relatively easy to synthesize and to modify, they have attracted great attention as materials for SCOSCs. Polymer fragments with reactive sites in the end group are the prerequisite for obtaining di-block copolymers. As the synthesis methods for such fragments are limited, the types of materials and their photovoltaic performance are as well limited. ${ }^{47,59}$ By developing donor blocks except for polythiophene derivatives and employing new acceptor segments, a high PCE of $6.43 \%$ has been achieved for a di-block copolymer-based SCOSC, which showed excellent crystallinity and complementary absorption. ${ }^{60}$ Nevertheless, systematic investigations on the rigidity of the backbone framework, the nanophase separation morphology and the photo-physics are still lacking. More details about di-block copolymers could be found in recent reviews. ${ }^{46,47}$

The third category is D-A small molecules (e.g., dyads, oligomers) which frequently comprise conjugated backbones based on oligo(phenylenevinylenes) or oligothiophenes with fullerene or perylene bisimide (PBI)-type pendent groups. ${ }^{61}$ Compared with polymeric materials, D-A small molecules offer reduced synthetic complexity and possess a well-defined chemical structure. The nature and length of the molecular spacer bridging $D$ and $A$, flexible non-conjugated or rod-like conjugated, polar or apolar, play as well an important role for the fundamental photophysical processes, as they influence the aggregation behavior of the molecules into supermolecular assemblies with segregated donor and acceptor domains. Due to the lack of a polymer backbone, such molecules need to form both electron and hole transport channels by molecular 

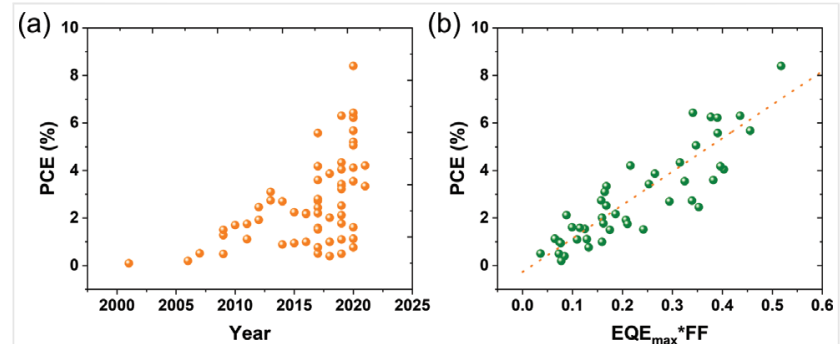

Figure 2 (a) Efficiency evolution of SCOSCs. (b) PCE as a function of $\mathrm{EQE}_{\max }{ }^{*} \mathrm{FF}$.

aggregation. Recently, an efficiency of $4.21 \%$ has been obtained by a fullerene-based D-A small molecule. ${ }^{62}$

\section{Photovoltaic Performance Development}

The efficiency evolution of SCOSCs in Figure 2a reveals that SCOSCs hardly managed to pass the 3\% milestone before 2017. Yet only after several years, efficiencies of $6.43 \%$ and $8.4 \%$ have been reported in 2020. As summarized in Table 1 , the continuously improved $J_{\mathrm{SC}}$ and fill factor (FF) contribute mostly to the recent success of SCOSCs. J $J_{\text {SC }}$ could be represented by the maximum of external quantum efficiency $\left(\mathrm{EQE}_{\mathrm{max}}\right)$ to some degree, indicating the capability of

Table 1 Photovoltaic parameters of SCOSCs

\begin{tabular}{|c|c|c|c|c|c|c|}
\hline Ref. & Category & $V_{\mathrm{OC}}(\mathrm{V})$ & $J_{s c}\left(m A c m^{-2}\right)$ & FF (\%) & PCE (\%) & $\mathrm{EQE}_{\max }$ \\
\hline 63 & M1 & 0.75 & 4.91 & 0.28 & 1.10 & 0.39 \\
\hline 64 & M2 & 0.99 & 2.61 & 0.62 & 1.61 & 0.16 \\
\hline 65 & M3 & 1.19 & 3.54 & 0.27 & 1.13 & 0.24 \\
\hline 66 & M4 & 0.88 & 3.30 & 0.44 & 1.28 & 0.40 \\
\hline 67 & M5 & 0.91 & 4.60 & 0.46 & 1.92 & 0.45 \\
\hline 68 & M6 & 0.97 & 7.02 & 0.36 & 2.44 & 0.46 \\
\hline 69 & M7 & 0.66 & 6.71 & 0.49 & 2.17 & 0.38 \\
\hline 70 & M8 & 0.88 & 5.90 & 0.35 & 1.75 & 0.60 \\
\hline 71 & M9 & 0.73 & 8.03 & 0.43 & 2.52 & 0.39 \\
\hline 37 & M10 & 0.98 & 7.50 & 0.44 & 3.22 & 0.43 \\
\hline 62 & M11a & 0.82 & 11.42 & 0.45 & 4.21 & 0.48 \\
\hline 62 & M11b & 0.80 & 8.39 & 0.41 & 2.74 & 0.41 \\
\hline 62 & M11c & 0.81 & 9.86 & 0.42 & 3.34 & 0.40 \\
\hline 72 & M12 & 1.04 & 5.32 & 0.49 & 2.70 & 0.60 \\
\hline 73 & P1 & 0.44 & 1.50 & 0.25 & 0.20 & 0.31 \\
\hline 74 & $\mathbf{P} 2$ & 0.79 & 4.04 & 0.48 & 1.54 & 0.26 \\
\hline 75 & P3 & 0.60 & 8.03 & 0.44 & 2.12 & 0.20 \\
\hline 76 & P4 & 0.74 & 6.72 & 0.36 & 1.77 & 0.45 \\
\hline 77 & P5 & 0.94 & 5.86 & 0.37 & 2.01 & 0.43 \\
\hline
\end{tabular}

Table 1 (Continued)

\begin{tabular}{|c|c|c|c|c|c|c|}
\hline Ref. & Category & $V_{\mathrm{OC}}(\mathrm{V})$ & $J_{\mathrm{sC}}\left(\mathrm{mA} \mathrm{cm}^{-2}\right)$ & $\mathrm{FF}(\%)$ & PCE (\%) & $\mathrm{EQE}_{\max }$ \\
\hline 78 & P6 & 0.51 & 5.02 & 0.59 & 1.52 & 0.41 \\
\hline 79 & P7 & 0.68 & 8.96 & 0.45 & 2.74 & 0.35 \\
\hline 80 & P8 & 1.23 & 5.20 & 0.47 & 3.10 & 0.35 \\
\hline 81 & P9 & 0.93 & 8.26 & 0.5 & 3.87 & 0.53 \\
\hline 38 & P10 & 0.80 & 9.32 & 0.46 & 3.43 & 0.55 \\
\hline 82 & P11 & 0.92 & 7.60 & 0.60 & 4.18 & 0.66 \\
\hline 83 & P12 & 1.05 & 8.31 & 0.50 & 4.34 & 0.63 \\
\hline 84 & P13 & 0.62 & 9.91 & 0.65 & 4.05 & 0.62 \\
\hline 85 & P14a & 0.68 & 13.3 & 0.62 & 5.58 & 0.63 \\
\hline 86 & P14b & 0.68 & 12.2 & 0.67 & 5.68 & 0.68 \\
\hline 60 & P15 & 0.85 & 12.21 & 0.62 & 6.43 & 0.55 \\
\hline 87 & P16 & 0.89 & 10.76 & 0.65 & 6.22 & 0.60 \\
\hline 39 & P17a & 0.90 & 10.8 & 0.65 & 6.32 & 0.67 \\
\hline 88 & P17b & 0.84 & 12.68 & 0.58 & 6.25 & 0.65 \\
\hline 57 & P18a & 1.00 & 8.20 & 0.62 & 5.06 & 0.56 \\
\hline \multirow[t]{2}{*}{57} & P18b & 0.94 & 12.81 & 0.69 & 8.40 & 0.75 \\
\hline & Further materia & & & & & \\
\hline 89 & Small molecule & 0.73 & 2.10 & 0.29 & 0.40 & 0.29 \\
\hline 90 & Small molecule & 0.90 & 1.89 & 0.28 & 0.50 & 0.26 \\
\hline 91 & Small molecule & 0.55 & 3.59 & 0.39 & 0.77 & - \\
\hline 92 & Small molecule & 0.50 & 4.79 & 0.46 & 1.11 & 0.28 \\
\hline 93 & Small molecule & 0.87 & 4.49 & 0.38 & 1.50 & 0.46 \\
\hline 94 & Small molecule & 0.82 & 9.17 & 0.45 & 3.35 & 0.46 \\
\hline 44 & Polymer & 0.83 & 0.42 & 0.29 & 0.10 & - \\
\hline 79 & Polymer & 0.54 & 3.21 & 0.30 & 0.51 & 0.12 \\
\hline 95 & Polymer & 0.75 & 2.41 & 0.29 & 0.52 & - \\
\hline 53 & Polymer & 0.79 & 3.93 & 0.32 & 1.0 & 0.23 \\
\hline 79 & Polymer & 0.57 & 7.03 & 0.41 & 1.58 & 0.28 \\
\hline 82 & Polymer & 0.69 & 7.54 & 0.53 & 2.73 & 0.64 \\
\hline 82 & Polymer & 0.78 & 8.05 & 0.57 & 3.60 & 0.67 \\
\hline 86 & Polymer & 0.62 & 10.4 & 0.55 & 3.55 & 0.59 \\
\hline 86 & Polymer & 0.63 & 10.9 & 0.60 & 4.12 & - \\
\hline 86 & Polymer & 0.68 & 11.6 & 0.64 & 5.21 & - \\
\hline 96 & Polymer & 0.51 & 2.57 & 0.37 & 0.49 & - \\
\hline 97 & Polymer & 0.39 & 3.72 & 0.53 & 0.77 & 0.25 \\
\hline 98 & Polymer & 0.57 & 4.30 & 0.34 & 0.89 & 0.45 \\
\hline 99 & Polymer & 1.08 & 1.95 & 0.45 & 0.95 & 0.17 \\
\hline 100 & Polymer & 0.43 & 5.29 & 0.43 & 1.00 & 0.37 \\
\hline 101 & Polymer & 0.54 & 6.15 & 0.51 & 1.70 & - \\
\hline 102 & Polymer & 1.10 & 4.80 & 0.41 & 2.20 & - \\
\hline 103 & Polymer & 1.11 & 4.73 & 0.42 & 2.24 & - \\
\hline 104 & Polymer & 0.48 & 8.14 & 0.63 & 2.46 & 0.56 \\
\hline 105 & Polymer & 1.12 & 6.0 & 0.39 & 2.60 & - \\
\hline 106 & Polymer & 0.52 & 9.8 & 0.55 & 2.80 & - \\
\hline 80 & Polymer & 1.14 & 5.0 & 0.45 & 2.74 & 0.35 \\
\hline
\end{tabular}


converting external photons into charges. ${ }^{107}$ As reported by Koster et al., FF is dominated by the competition between recombination and extraction of free charges, whereas high FF values indicate better charge extraction and less recombination losses. ${ }^{108}$ PCE shows a proportional relation to $\mathrm{EQE}_{\max }{ }^{*} \mathrm{FF}$ value as shown in Figure $2 \mathrm{~b}$. This phenomenon suggests that the recent efficiency enhancement is the result of a balanced combination of increased absorption, enhanced transport and extraction as well as suppressed recombination. Accordingly, to reflect the progress in efficiency, we categorized the SCOSC materials by their $\mathrm{EQE}_{\max }$ and $\mathrm{FF}$ parameters as follows: (1) low $\mathrm{EQE}_{\max }(<0.4)$ and low FF $(<0.4),(2)$ moderate $\mathrm{EQE}_{\max }(0.4-0.5)$ and moderate FF (0.4-0.6), or $\mathrm{EQE}_{\max }{ }^{*} \mathrm{FF}(0.16-0.3)$, (3) high $\mathrm{EQE}_{\text {max }}(>0.5)$ and high $\mathrm{FF}(>0.6)$, or $\mathrm{EQE}_{\max }{ }^{*} \mathrm{FF}>0.3$. The polymeric materials for SCOSCs are designated as P1-P19 and the D-A small molecules as M1-M12.

\section{SCOSCs with Low $\mathrm{EQE}_{\max }$ and $\mathrm{FF}$}

SCOSCs have stayed with low efficiencies as well as low $\mathrm{EQE}_{\max }(<0.4)$ and $\mathrm{FF}(<0.4)$ for quite a long time, and even some recent materials fall in this category, showing the chemical complexity of optimizing SCOSCs. More detailed information about the early-stage SCOSCs can be found in the review by Roncali et al. ${ }^{11,36}$

Herein, few examples are discussed and the chemical structures of related materials are shown in Figure 3. In 2006, Krausch's group reported a di-block copolymer P1 employing PBI as an acceptor unit, and they found that the proper percolation of charges in solar cells is possible with the self-assembled nanostructure. A photovoltaic device with $0.2 \%$ efficiency, as well as an $\mathrm{EQE}_{\max }$ of 0.31 and a $\mathrm{FF}$ of 0.25 , was obtained. ${ }^{73}$ In 2017 , Lee et al. synthesized two types of novel poly(3-alkylthiophene)-free $(\mathrm{D})_{n}-b-(\mathrm{A})_{m}$ conjugated block copolymers P2, PTQI-block-PNDISs composed of quinoxaline-thiophene and naphthalene dicarboximide-selenophene blocks, in which the two blocks were connected either by direct conjugation or a flexible 6carbon alkyl spacer. ${ }^{74}$ The insertion of a flexible spacer limited charge recombination and induced an increase of PCE from $0.36 \%$ to $1.54 \%$. In 2017 , Li's group designed a series of double-cable polymers P3 based on diketopyrrolopyrrole (DPP)-polymer backbone and PBI side chains with 3,4 or 5 thiophene groups on the backbone, and observed their effect on adjusting crystallinity of conjugated backbone and thus nanophase separation. The SCOSCs based on the P3 with 5 thiophene groups exhibited a PCE of 2.12\% upon thermal annealing at $200{ }^{\circ} \mathrm{C}$, originated from a decent FF of 0.44 and a low $\mathrm{EQE}_{\text {max }}$ of only 0.2 but with a broad photoresponse (300-900 nm). ${ }^{75}$ In 2019, Cabanetos et al. designed a series of push-pull dyads M1 employing triphenylamine as a donor and $\mathrm{PC}_{61} \mathrm{BM}$ as an acceptor

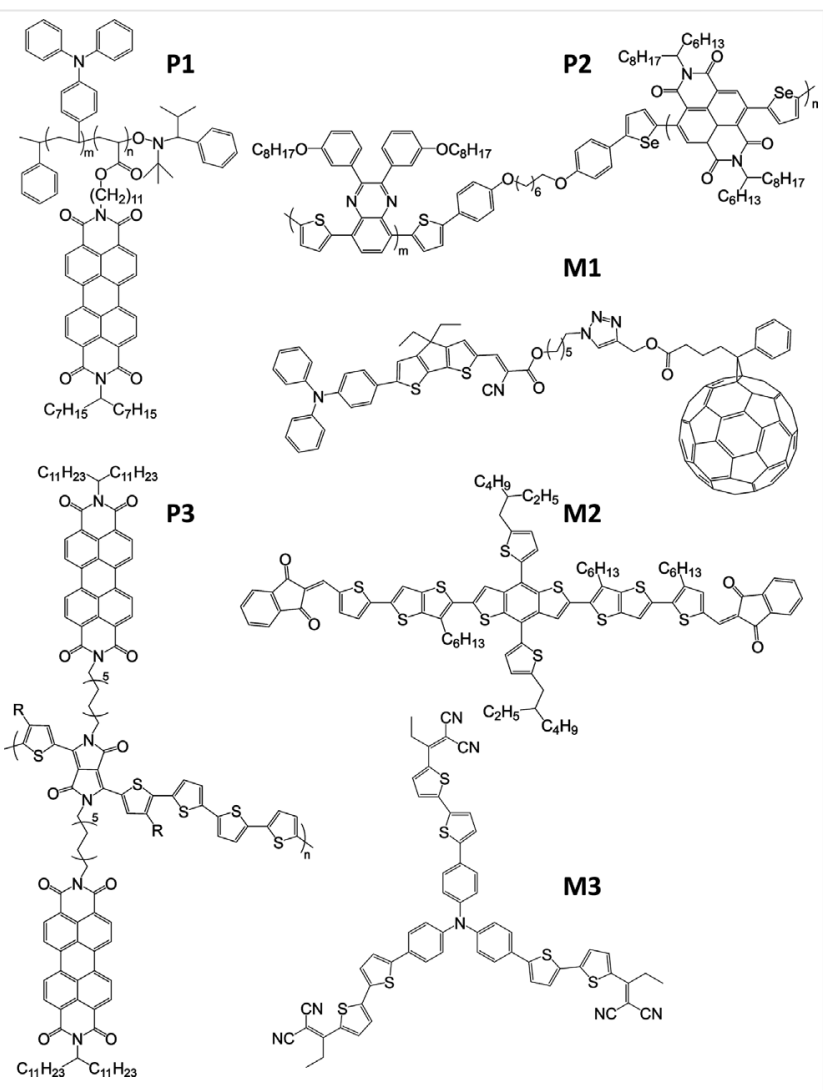

Figure 3 Chemical structures of P1-P3 and $\mathbf{M} 1-\mathbf{M} 3$ (low EQE max $_{\text {and }}$ FF).

with three different $\pi$-connectors to adjust the electrochemical and photovoltaic properties, in which the cyclopentadithiophene connector endowed the highest efficiency of $1.1 \%{ }^{63}$ Recently, Wei et al. reported a SCOSC employing a small-molecule material M2, which showed an efficiency of $1.61 \%$ upon $90{ }^{\circ} \mathrm{C}$ thermal annealing treatment. ${ }^{64}$ Although the FF (0.62) was excellent, however, the overall EQE remained too low (0.16). Interestingly, M2 worked well as an electron donor, and displayed a PCE reaching $8.47 \%$ when blending with 50\% [6,6]-phenyl C71 butyric acid methyl ester ( $\left.\mathrm{PC}_{71} \mathrm{BM}\right)$. The unique properties of M2 could shed a light on the mechanism of charge generation. In 2020, a star-shaped $\pi$-conjugated D-A oligomer M3 was reported by Paraschuk et al., and a high $V_{\mathrm{OC}}$ of $1.19 \mathrm{~V}$ was observed. However, the low FF (0.27) and $\mathrm{EQE}_{\max }(0.24)$ resulted in a low PCE of $1.13 \%$, which was ascribed to the field-assisted charge generation in the limit of weak electric fields. ${ }^{65}$

\section{SCOSCs with moderate $\mathrm{EQE}_{\max }$ and FF}

When it comes to SCOSCs with moderate $\mathrm{EQE}_{\max }$ (0.4-0.5) and FF (0.4-0.6), less materials emerge than the 

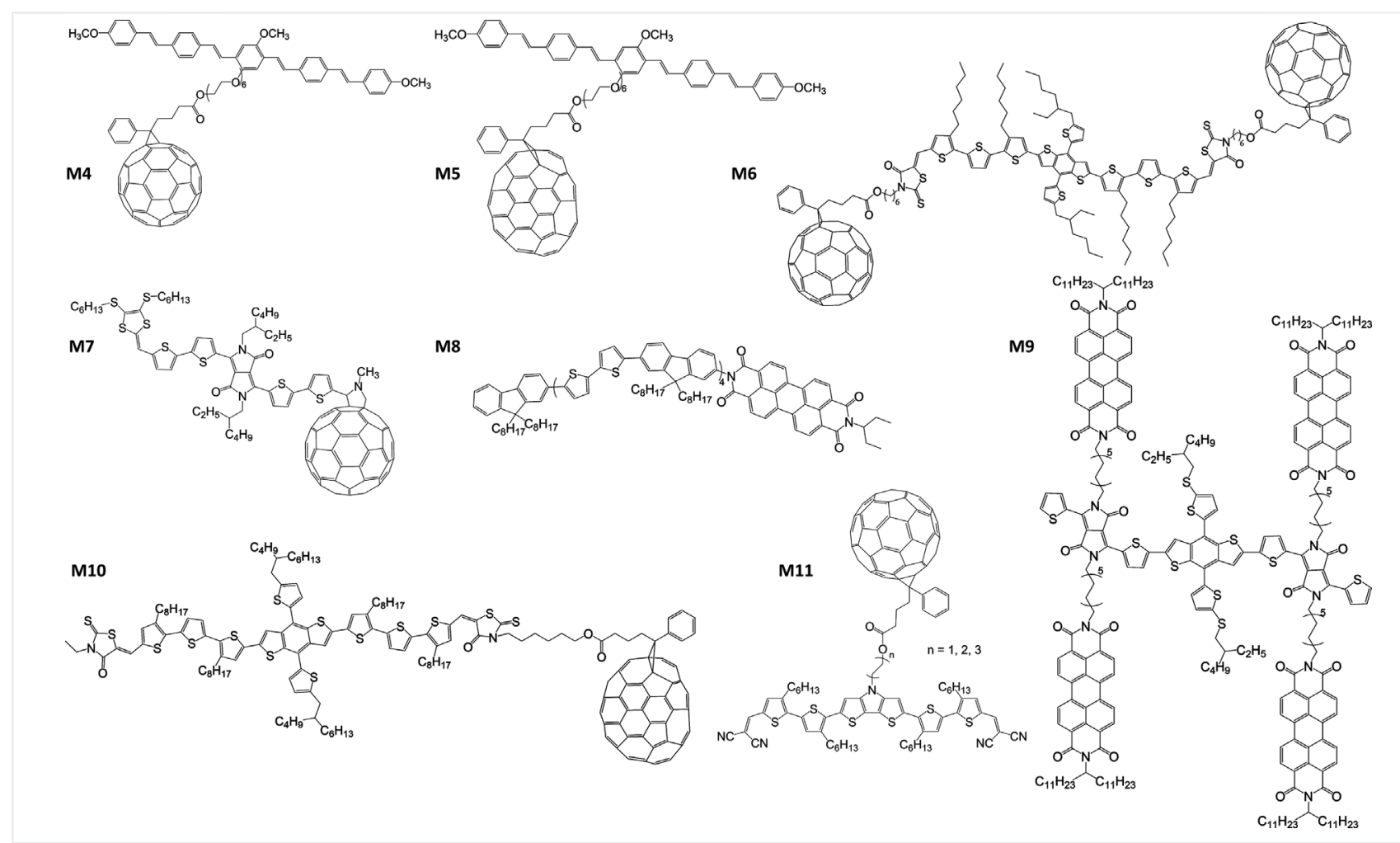

Figure 4 Chemical structures of M4-M11 (moderate $\mathrm{EQE}_{\max }$ and FF).

first category (low EQE $E_{\max }$ and FF). Chemical structures of some examples of the related materials are shown in Figure 4 (M4-M11) and Figure 5 (P4-P10).

D-A small molecules have been extensively researched and reported due to a relatively straightforward synthesis. In 2009, Hashimoto and co-workers reported a novel oligo ( $p$-phenylenevinylene)-fullerene dyad M4 with strong intermolecular $\pi-\pi$ interactions between the highly crystalline donor groups. A PCE of up to $1.28 \%$ was achieved for M4-based SCOSCs. ${ }^{66}$ In 2012, the same group introduced $\mathrm{PC}_{71} \mathrm{BM}$ replacing the $\mathrm{PC}_{61} \mathrm{BM}$ acceptor into dyad M5; an extension of the absorption and a thermal annealing process at $110{ }^{\circ} \mathrm{C}$ for 5 min promoted PCE to $1.92 \%{ }^{67}$ Very recently in 2017, Nguyen et al. synthesized a new type of conjugated small molecule $\mathbf{M 6}$ with a p-type benzodithiophene (BDT)rhodanine center and two terminal $\mathrm{PC}_{61} \mathrm{BM}$ linked by 6 carbon alkyl spacers. ${ }^{68}$ The broad absorption rendered a high $J_{\mathrm{SC}}>7.0 \mathrm{~mA} \mathrm{~cm}{ }^{-2}$ and an $\mathrm{EQE}_{\max }$ of $46 \%$. The SCOSC device showed a PCE of 2.44\%. In 2016, Narayanaswamy et al. designed a dyad $\mathbf{M 7}$ containing a dithiafulvalenefunctionalized DPP as a donor and $C_{60}$ as an acceptor. ${ }^{69}$ The introduction of DPP helped to form long-range ordering and improved charge transport. The broad absorption from 500 to $800 \mathrm{~nm}$ and the balanced hole and electron mobility jointly contributed to a PCE of $2.17 \%$ with a FF of 0.49 . In 2011, Bu et al. synthesized a series of liquid crystalline dyads M8 with substituted oligo(fluorene-alt-bithiophene) as a donor and PBI as acceptor segments. Different lengths of donor segments were employed for forming different periods of ordered alternating D-A lamellae, and the highest efficiency of $1.75 \%$ was achieved after solvent vapor annealing (SVA). ${ }^{70}$ Recently in 2019, Li and co-workers introduced sulfur heteroatoms in a DPP-PBI-based dyad M9 to tune the crystalline and nanophase separation and form well-ordered lamellar and fibrous structures. Accordingly, a high $J_{\mathrm{SC}}$ of $8.03 \mathrm{~mA} \mathrm{~cm}-2$ and a PCE of $2.52 \%$ were achieved. $^{71}$

In 2019, Min and co-workers developed a dyad M10 with BDT-rhodanine-PC ${ }_{71} \mathrm{BM}$ structure $\left(\mathrm{Rh}-\mathrm{PC}_{71} \mathrm{BM}\right)$ linked by a 12-atom spacer. Upon thermal annealing at $100{ }^{\circ} \mathrm{C}$, the photoluminescence was quenched by $93.3 \%$, indicating effective exciton dissociation, and the molecular ordering with pronounced intermolecular $\pi-\pi$ interactions rendered balanced hole and electron mobility, giving an efficiency of 3.22\% for M10-based SCOSCs. ${ }^{37}$ Moreover, the energy loss calculation revealed a low non-radiative recombination, although not quite fully understood, still giving some experience for future research. Most recently, Bäuerle's group reported a series of dyads M11 employing an oligothiophene with covalently linked fullerene units with a 2, 4, or 6 carbon chain spacer. ${ }^{62}$ For the M11c with $6 \mathrm{C}$ spacer, mobility data indicated that before SVA, aggregated 

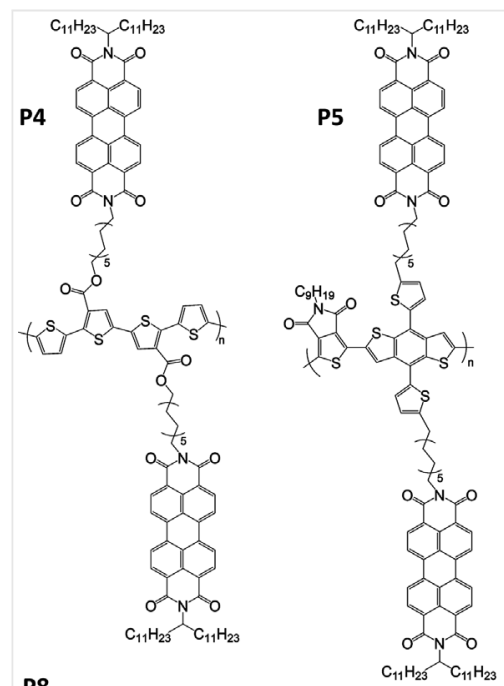

P8
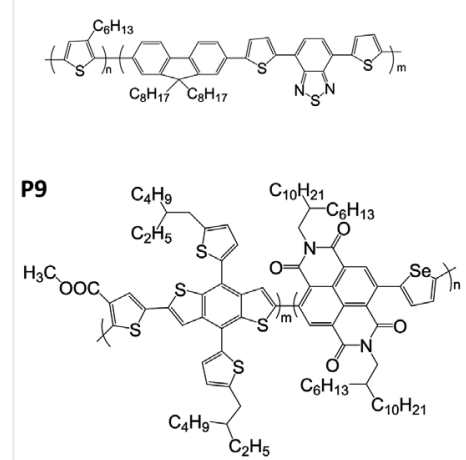

P10a
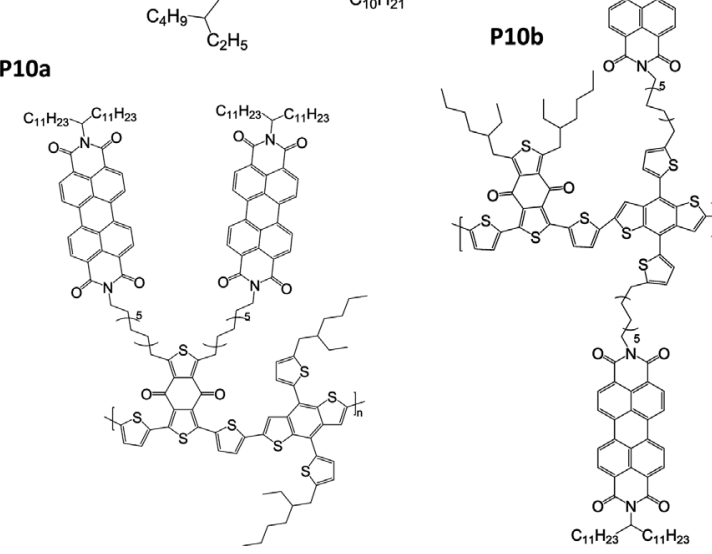

Figure 5 Chemical structures of P4-P10 (moderate $\mathrm{EQE}_{\max }$ and FF).

fullerene domains already existed, while the oligothiophene parts as well displayed decent aggregation due to the longer linker. In contrast, M11a with the shortest linker (2C) could hardly form ordered stacking, and only after SVA treatment, a substantially improved molecular re-arrangement occurred, giving the highest efficiency of $4.21 \%$, in agreement with charge transport studies and morphology characterization. Combined with theoretical calculations, the results consistently indicated a lamellar supramolecular order of the dyads with D-A phase separation smaller than $2 \mathrm{~nm}^{62}$
In 2019, Li's group designed a double-cable conjugated polymer P4 containing both a crystalline conjugated backbone and PBI side units. By employing the high boiling point solvent dichlorobenzene, well-ordered nanostructures were formed, contributing to a PCE of $1.77 \%$, a FF of 0.36 and an $\mathrm{EQE}_{\max }$ of $0.45 .{ }^{76}$ The same group also reported another double-cable polymer P5 with a thienopyrroledione-based backbone and PBI as side units, which showed a PCE of $2.01 \%$ without post-treatment. Nevertheless, $\mathrm{EQE}_{\max }$ and FF values were only 0.43 and 0.37 , respectively. ${ }^{77}$

In 2017, Tajima et al. reported the synthesis of heteroblock copolymers P6 consisting of P3HT and fullereneattached poly(3-alkylselenophene) based on the idea of creating a cascade of energy levels to limit charge recombination. ${ }^{78}$ After thermal treatment at $250{ }^{\circ} \mathrm{C}$, a clear microphase-separated nanostructure of $\sim 30 \mathrm{~nm}$ appeared, and the selenophene-based SCOSCs gave a PCE of $1.52 \%$ with a FF of 0.59 and an $\mathrm{EQE}_{\max }$ of $0.41 .^{78}$ In 2017, Li and coworkers have developed three new double-cable polymers P7 based on DPP-polymer backbone and PBI side chains. By increasing the length of alkyl spacers from 6 to 12 carbons between DPP and PBI units and by introducing alkylthiothiophene groups on the BDT unit, the polymers were found to show improved crystallinity and better nanophase separation, leading to an increase of PCE from $0.51 \%$ to $2.74 \%$, and FF from 0.29 to 0.46 and $\mathrm{EQE}_{\max }$ to 0.35 . These results confirm that the optimization of the linker is a crucial parameter that controls not only phase separation but also indirectly the packing arrangement of the donor and acceptor subcomponents. ${ }^{79}$ Back in 2013, Guo et al. demonstrated that P3HT-block-poly((9,9-dioctylfluorene)2,7-diyl-alt-[4,7-bis(thiophen-5-yl)-2,1,3-benzothiadiazole]-2',2"-diyl) (P3HT-b-PFTBT) di-block copolymers P8 could self-assemble into in-plane lamellar morphologies with alternating electron donor and acceptor domains and a dominant face-on orientation with the crystalline P3HT block. ${ }^{80}$ An efficiency of $3.1 \%$, a remarkable $V_{\mathrm{OC}}$ of $1.2 \mathrm{~V}$, a FF of 0.47 and a $J_{\mathrm{Sc}}$ above $5 \mathrm{~mA} \mathrm{~cm}{ }^{-2}$ with an $\mathrm{EQE}_{\max }$ of 0.35 were achieved. ${ }^{80}$ In 2018, Lee and co-workers demonstrated a fully di-block copolymer P9, containing a wide bandgap BDT-thiophenecarboxylate-based copolymer and a narrow bandgap naphthalenedicarboximide-selenophene-based copolymer, leading to a broad complementary absorption. ${ }^{81}$ Optical characteristics indicated complete photoluminescence quenching because of efficient photo-induced inter-/ intramolecular charge transfer states with a fast decaying lifetime. A PCE of $3.87 \%$ with a $V_{\mathrm{OC}}$ of $0.93 \mathrm{~V}$, a FF of 0.50 and a $J_{\mathrm{SC}}$ of $8.26 \mathrm{~mA} \mathrm{~cm}{ }^{-2}$ with an $\mathrm{EQE}_{\max }$ of 0.53 were reported. ${ }^{81}$ To investigate crystalline balance (cooperativity) between donor and acceptor segments in double-cable polymers, Li et al. have designed two double-cable polymers with the same poly[(2,6-(4,8-bis(5-(2-ethylhexyl-3-fluoro) thiophen-2-yl)-benzo[1,2-b:4,5-b']dithiophene))-alt-(5,5(1',3'-di-2-thienyl-5',7'-bis(2-ethylhexyl)benzo[1',2'- 
c:4',5'-c']dithiophene-4,8-dione)] (PBDBT) donor backbone and PBI acceptor side chains, one (P10a) with PBI units located asymmetrically and slantingly at one side along the conjugated backbones, another one (P10b) with PBI units at two sides of the backbone symmetrically and perpendicularly. ${ }^{38}$ After thermal annealing, both conjugated backbones and PBI side units in P10b tended to form ordered nanostructures, while PBI side units in P10a dominated the crystallization and hampered the crystallization of conjugated backbones. P10b showed good crystalline cooperativity between conjugated backbones and PBI side units, resulting in a decent PCE of up to $3.43 \%$ with a decent FF of 0.46 and $\mathrm{EQE}_{\text {max }}$ of 0.55 in SCOSCs, while P10a with poor crystalline cooperativity exhibited PCE values below $2.42 \%{ }^{38}$

\section{SCOSCs with High EQE $\mathrm{max}_{\max }$ and FF}

The SCOSCs with high $\mathrm{EQE}_{\max }(>0.5)$ and FF $(>0.6)$ normally have efficiencies higher than $4 \%$. However, the related materials are very limited and mainly based on polymers. All these materials are shown in Figure 6. Only one molecular material M12 emerged with substituted oligo (fluorene-alt-bithiophene) as a donor and PBI as acceptor segments. By introducing a dithienyl benzothiadiazole group in M12, a PCE of $2.7 \%$ with a $J_{S C}$ of $5.32 \mathrm{mAcm}^{-2}\left(\mathrm{EQE}_{\max }\right.$ of 0.65$)$, a FF of 0.47 and $a V_{O C}$ of $1.04 \mathrm{~V}$ were achieved. ${ }^{72}$ All other materials are double-cable polymers and di-block copolymers.

One attempt by Li's group was by developing a doublecable polymer P11 containing a linear conjugated backbone

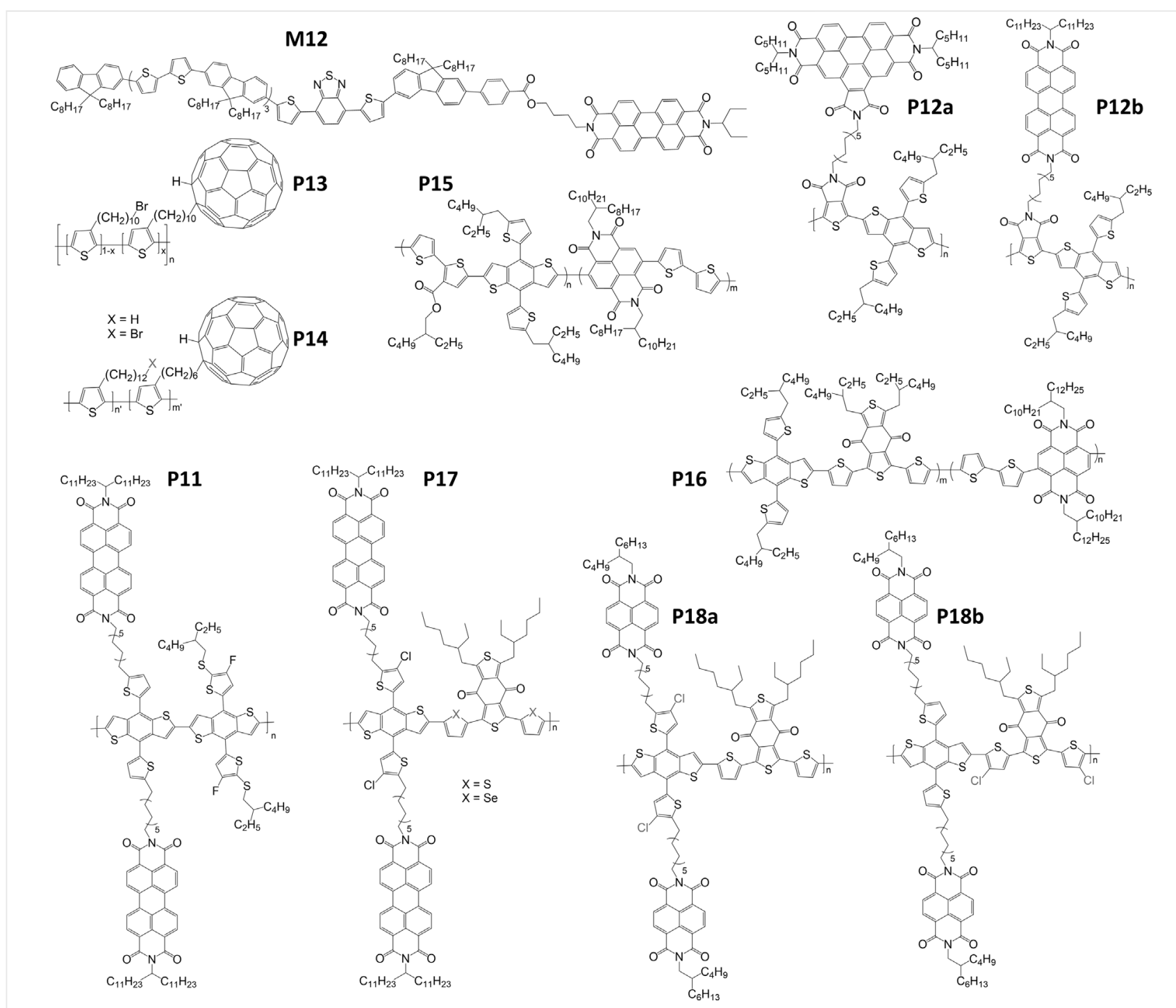

Figure 6 Chemical structures of M12 and P11-P18 (high EQE $E_{\max }$ and FF). 
to tune the crystallinity of double-cable polymers. ${ }^{82}$ The linear conjugated backbone acted as a scaffold for the crystallization of the large $\pi$-conjugated PBI groups, to provide a double-cable nanophase separation of donor and acceptor phases. The optimized nanophase separation enabled efficient exciton dissociation as well as balanced charge transport as evidenced by a high PCE of $4.18 \%$ with a high $\mathrm{FF}$ of 0.6 and an $\mathrm{EQE}_{\max }$ of 0.66 after thermal annealing treatment for active layer at $150{ }^{\circ} \mathrm{C} .{ }^{82}$ Another method introduced by Li's group to improve the electron transport in double-cable polymers P12 was by introducing a parallel and large benzo[ghi]perylenetriimide (BPTI) (P12a) into the side chains, instead of the conventional PBI side units (P12b), to create more chance for the contact between adjacent BPTI units. ${ }^{83}$ The new electron-deficient BPTI units were found to lower the crystallinity of conjugated backbone, resulting in a balanced charge transport. Therefore, P12a provided a PCE of $4.34 \%$ (FF, 0.5; $\mathrm{EQE}_{\text {max }}, 0.63$ ) in SCOSCs compared to the efficiency of $1.92 \%$ for P12b based on the polymer with PBI side units. ${ }^{83}$ Except for the abovementioned NFA-based double-cable polymers, fullerenebased double-cable polymers could as well reach high $\mathrm{FF}$ and $\mathrm{EQE}_{\max }$. As reported by Pierini and co-workers, regioregular thiophenic copolymers P13 grafted by $\mathrm{PC}_{61} \mathrm{BM}$ at the end of a decamethylenic plastifying side chain have been successfully synthesized and showed a PCE of $4.05 \%$ with a high FF of 0.65 and an $\mathrm{EQE}_{\max }$ of $0.62 .^{84}$ Moreover, the presence of the halogen group was exploited for the photo-crosslinking of the active layer immediately after thermal annealing, leading to excellent stability. In 2017, Pierini et al. reported efficient SCOSCs based on fullerene-grafted polythiophenes P14a fabricated by electrospinning. The well-packed and properly oriented polymer chains rendered an efficiency of $5.58 \%{ }^{85}$ Later on, reported by the same group, based on the same structure but with $\mathrm{Br}$-end-capped groups for photo-crosslinking, a similar double-cable polymer P14b (also resembling P13) exhibited an efficiency of 5.68\% (FF, 0.67; $\mathrm{EQE}_{\max }, 0.68$ ), which is remarkably high for a P3HT-PCBM type system. ${ }^{86}$ SCOSCs based on P14 are the only ones showing efficiencies higher than $5 \%$ employing fullerene as acceptors; the others are all based on NFAs.

Most recently, Chio's group exploited a highly crystalline di-block copolymer (PBDT2T- $b$-N2200) (P15) with a broad complementary absorption behavior owing to a wide-band gap donor (PBDT2T) and a narrow-band gap acceptor (N2200). ${ }^{60}$ The resulted SCOSCs showed an efficiency of 6.43\% (FF, 0.62; $\mathrm{EQE}_{\max }, 0.55$ ), 2.4 times higher than the corresponding $\mathrm{BHJ}$ solar cells, originated from a highly improved surface and internal morphology, as well as a more efficient photo-induced electron transfer evidenced by $a$ fast photoluminescence decay. In addition, the PBDT2T- $b$ N2200 film showed high crystallinity through an effective self-assembly of each block during thermal annealing and a predominant face-on chain orientation favorable to a verticaltype SCOSCs. ${ }^{60}$ Also developed by the same group, the diblock copolymer P(BDBT-co-NDI2T), P16, with BDBT units as the donor and NDI2T units as the acceptor had a relatively smoother surface and morphology as compared to the corresponding blended film. The decent uniformity of surface charge and the strong absorption band from 500 to $650 \mathrm{~nm}$ explained the high PCE of $6.22 \%\left(\mathrm{FF}, 0.65 ; \mathrm{EQE}_{\max }, 0.6\right)$ at $\mathrm{AM}$ $1.5 \mathrm{G}$ condition and $12.7 \%$ at indoor light (500 lux). ${ }^{87}$

Li's group recently reported a series of highly efficient double-cable polymers with efficiencies higher than 6\%.39,57,88 Employing BDBT as donor units and PBI as acceptor units, Li et al. explored a double-cable polymer P17a and used thermal annealing at different temperatures to tune the crystallinity. ${ }^{39}$ As shown in Figure 7, P17a exhibited a significantly enhanced crystalline structure when increasing the annealing temperature. With a high annealing temperature $\left(230^{\circ} \mathrm{C}\right)$, both the backbones and PBI side units could self-organize into ordered nanostructures. This enabled efficient charge transport and low charge recombination, resulting in a high efficiency of $6.32 \%$ (FF, 0.65; $\mathrm{EQE}_{\max }, 0.67$ ) in P17a-based SCOSCs. ${ }^{39}$ By simply changing the sulfur atoms to selenium atoms in the backbone, a new double-cable polymer P17b with a redshifted absorption spectrum was obtained, ${ }^{88}$ giving a higher photocurrent of $12.68 \mathrm{~mA} \mathrm{~cm} \mathrm{~cm}^{-2}$, compared to $10.83 \mathrm{~mA} \mathrm{~cm}^{-2}$ for P17a. A high-lying frontier energy level and good crystallinity were also achieved, while the planar and crystalline conjugated backbones causing relatively poor crystalline cooperativity between the conjugated backbones and the electron acceptor side chains, leading to a relatively low FF (0.58) in SCOSCs due to a possibly strong charge recombination. ${ }^{88}$ Nevertheless, a PCE of $6.25 \%$ $\left(\mathrm{EQE}_{\max }, 0.65\right)$ was obtained after thermal annealing at $230^{\circ}$ $\mathrm{C}$, quite comparable to the one of P17a. Most recently, Li et al. reported SCOSCs with a record efficiency of $8.40 \%$ from P18 with BDBT as the backbone donor and naphthalene diimides (NDIs) as side chain acceptors. ${ }^{57}$ Two polymers P18a and P18b with extra chlorine $(\mathrm{Cl})$ atoms located at different positions on the conjugated backbones were obtained. When $\mathrm{Cl}$ atoms were positioned at the main chains (P18b), the polymer formed a more twisted backbone, enabling better miscibility with the NDI side units. This improved the interface contact between conjugated backbones and side units, resulting in efficient conversion of excitons into free charges. This insight revealed a winning strategy to influence charge generation in SCOSCs: controlling miscibility between conjugated backbones and aromatic side units in double-cable conjugated polymers. Overall, a PCE of $8.4 \%$ was obtained, together with an EQE over 0.75 and a FF close to 0.70 as shown in Figure 8.

To summarize, in most SCOSCs with high $\mathrm{EQE}_{\max }$ and FF, P3HT and PCBM units were replaced by units such as BDT, 

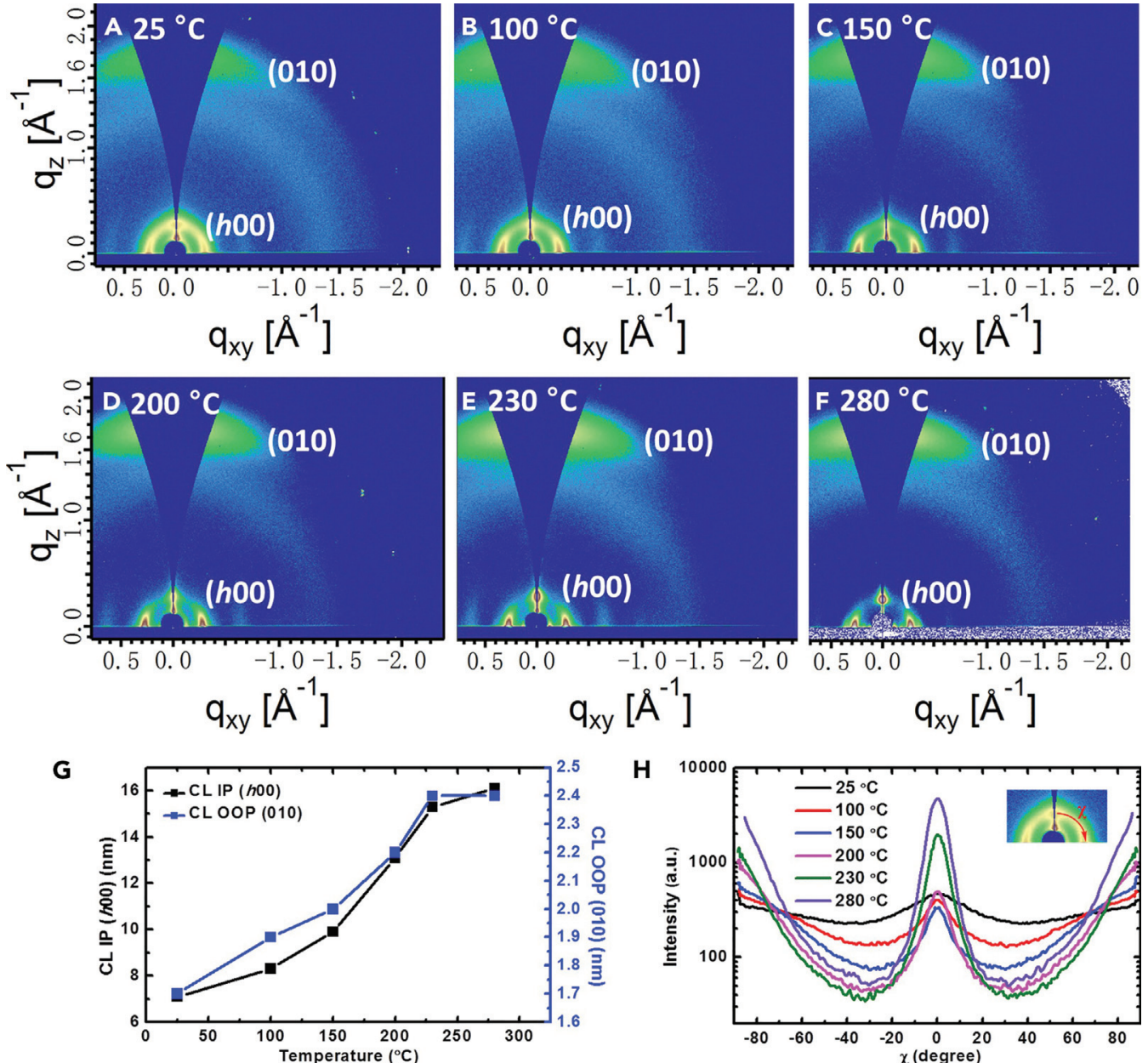

Figure 7 Characteristics of P17a thin films thermally annealed at different temperatures for 10 min. (A-F) GIWAXS patterns. (G) Coherence length of lamellar stacking at $q \approx 0.28 \AA^{-1}$ and $\pi-\pi$ stacking calculated from $(010)$ diffraction peaks related to annealed temperature.(H) Pole figure extracted from (h00) diffraction peaks related to temperature. Reproduced with permission from Ref. ${ }^{39}$. Copyright 2019 Elsevier.

(a)

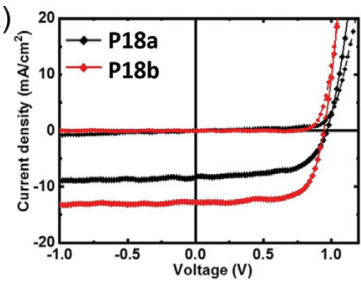

(b)

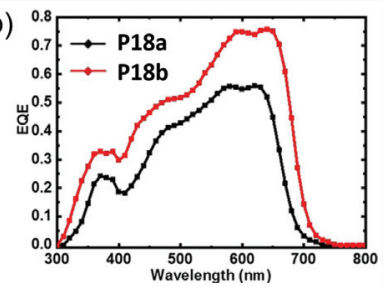

Figure 8 Characteristics of P18-based SCOSCs. a) J-V characteristics in dark (dashed line) and under white light illumination (solid line). b) EQE of the optimized SCOSCs. Reproduced with permission from Ref. ${ }^{57}$ Copyright 2020 John Wiley and sons.

BDBT, N2200, which serve as well common high-efficiency donor or acceptor units for BHJ systems. With an improved understanding of the governing processes, especially the linker connection pattern, the crystalline cooperation

between donor and acceptor and, to some surprise, the flexibility of the polymeric backbone, high temperature post-treatments allowed the formation of stable and efficient nanophases. The observation that the highest performance was frequently observed for high temperature post-treated nanostructures cannot be emphasized enough. A high temperature annealing step followed by slow cooling inevitably generates nanostructures which are close to their thermodynamic equilibrium. Such nanostructures are expected to be stable as well under long-term thermal stress - a hypothesis which will be discussed in more detail in the next section. With the improved scientific understanding on how to design highly efficient materials for SCOSCs, one can expect that efficiency will quickly rise to $10 \%$. At such high performance, the operating stability of SCOSC has to come into focus. 


\section{Stability of SCOSCs}

A strong motivation to develop SCOSCs is to obtain higher stability compared to BHJ-based solar cells. Unfortunately, the reported stability data on SCOSCs are still very limited. However, recently, with the rapid improvement of SCOSCs' efficiencies, the stability characterization is becoming more and more important regarding future industrial application. Herein, the stability of SCOSCs is introduced and discussed under three conditions, including shelf lifetime, thermal stability and stability under illumination.

\section{Shelf Stability}

The shelf stability of devices based on di-block copolymer P9 was evaluated for unencapsulated devices stored under ambient conditions and by measuring the $J-V$ characteristics under AM $1.5 \mathrm{G}$ at room temperature for over $1000 \mathrm{~h}$, according to the ISOS-D-1 (shelf) protocol. ${ }^{109}$ P9-based devices (chemical structure shown in Figure 5) retained $\sim 80 \%$ of its initial PCE for over $1000 \mathrm{~h}$, while the corresponding $\mathrm{BHJ}$-based devices retained only $\sim 40 \%$ of their initial PCE, due to a decrease in $J_{S C}$ associated with aggregation within the active layer. ${ }^{81}$ Devices based on another di-block copolymer P15 (chemical structure shown in Figure 6) showed as well superior shelf stability compared to the corresponding BHJ-based solar cells and maintained $90.1 \%$ and $59.5 \%$ of their initial PCE values, respectively. ${ }^{60}$ The different stability trends were accompanied by morphology investigations. AFM analysis showed large-sized phase separation for the BHJ composite, while SCOSCs retained a similar morphology after long-term stability testing. ${ }^{60,81}$

\section{Thermal Stability}

Several SCOSCs have been characterized under thermal aging conditions. One of the tests was conducted by Miyanishi et al. on a fullerene-attached all-semiconducting di-block copolymer in $2010 .{ }^{101}$ Thermal stability of the SCOSCs was measured at $130{ }^{\circ} \mathrm{C}$. The devices showed a small change in PCE from $1.59 \%$ to $1.50 \%$ after annealing at $130{ }^{\circ} \mathrm{C}$ for $80 \mathrm{~h}$, maintaining $94.3 \%$ of their initial performance. In the same period, the efficiency of corresponding BHJ-based solar cells dropped from $3 \%$ to $0.6 \%$. The formation of needle-like PCBM aggregations with a size of about $50 \mu \mathrm{m}$ was blamed for the rapid degradation. ${ }^{101}$ Later in 2017 , Nguyen and co-workers reported the thermal stability of a D-A small molecule M6 with an efficiency of 2.4\% (chemical structure shown in Figure 4) ${ }^{68}$ M6-based SCOSCs showed even no degradation of PCE at $80{ }^{\circ} \mathrm{C}$ for $100 \mathrm{~h}$ without any change in the surface morphology, while the BHJ-based OSCs displayed a fast decay in PCE to $\approx 80 \%$ of the initial value within 10 min via facile aggregation of PCBMs. ${ }^{68}$

Recently in 2020, Min et al. reported the thermal stability of a similar D-A small molecule M10 but with $\mathrm{PC}_{71} \mathrm{BM}$ as the acceptor unit (chemical structure shown in Figure 4), which showed a higher efficiency of 3.22\%. ${ }^{37}$ The device employed PEDOT:PSS (poly(3,4-ethylenedioxythiophene):poly(styrene-sulfonate)) and PDINO (perylene diimide functionalized with amino $\mathrm{N}$-oxide) as interface layers. As shown in Figure 9a, after thermal annealing in a nitrogen atmosphere at $85{ }^{\circ} \mathrm{C}$ for $400 \mathrm{~h}$, M10-based SCOSCs only had degraded to $83 \%$ of their initial efficiency, while the efficiency of corresponding $\mathrm{BHJ}$-based solar cells dropped to $16 \%$ in the same period. After $24 \mathrm{~h}$ at $120{ }^{\circ} \mathrm{C}, \mathrm{M10}$-based SCOSCs still displayed decent performance of about $84 \%$ of their initial performance. ${ }^{37}$ Similar phenomena have also been observed for P13-based SCOSCs (chemical structure shown in Figure 6), which possessed superior thermal stability compared with the BHJ-based OSCs. ${ }^{84}$ These findings strongly underline that SCOSCs have superior stability compared to their BHJ composites.
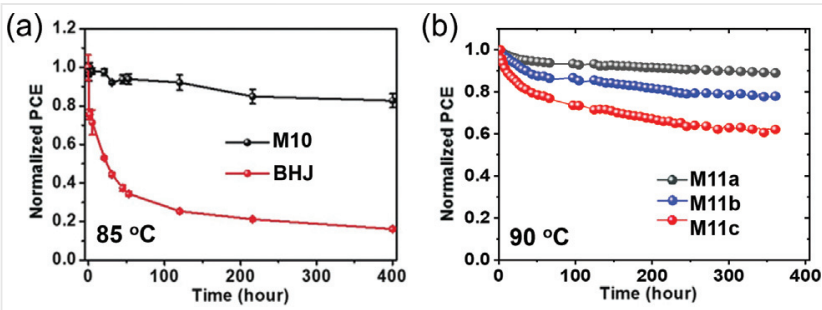

Figure 9 Thermal stability measurements of (a) M10-based SCOSCs and the corresponding $\mathrm{BHJ}$ solar cells at $85^{\circ} \mathrm{C}$. Reproduced with permission from Ref. ${ }^{37}$. Copyright 2019 , John Wiley and sons. Thermal stability measurements of (b) $\mathbf{M 1 1}$-based SCOSCs at $90^{\circ} \mathrm{C}$. The test was performed in nitrogen atmosphere without light exposure. ${ }^{62}$

However, this does not necessarily mean that all SCOSCs are highly stable, even though large-scale D-A phase segregation or accumulation is hindered. Deep insight was gained by the work from the Bäuerle group on the thermal stability of a series of D-A small molecules. The molecules M11a-c had exactly the same donor and acceptor units but differently long alkyl space linkers (chemical structure shown in Figure 4). ${ }^{62}$ This is the first report regarding the stability comparison among a series of SCOSCs and it is important to understand the freedom of movement such a dyad can undergo as a function of spacer length. Macroscopic diffusion of molecules can be excluded as a relevant degradation mechanism, as thermal stress can only twist, rotate or rearrange the relative orientation of the single molecules to each other. The length of the spacer 

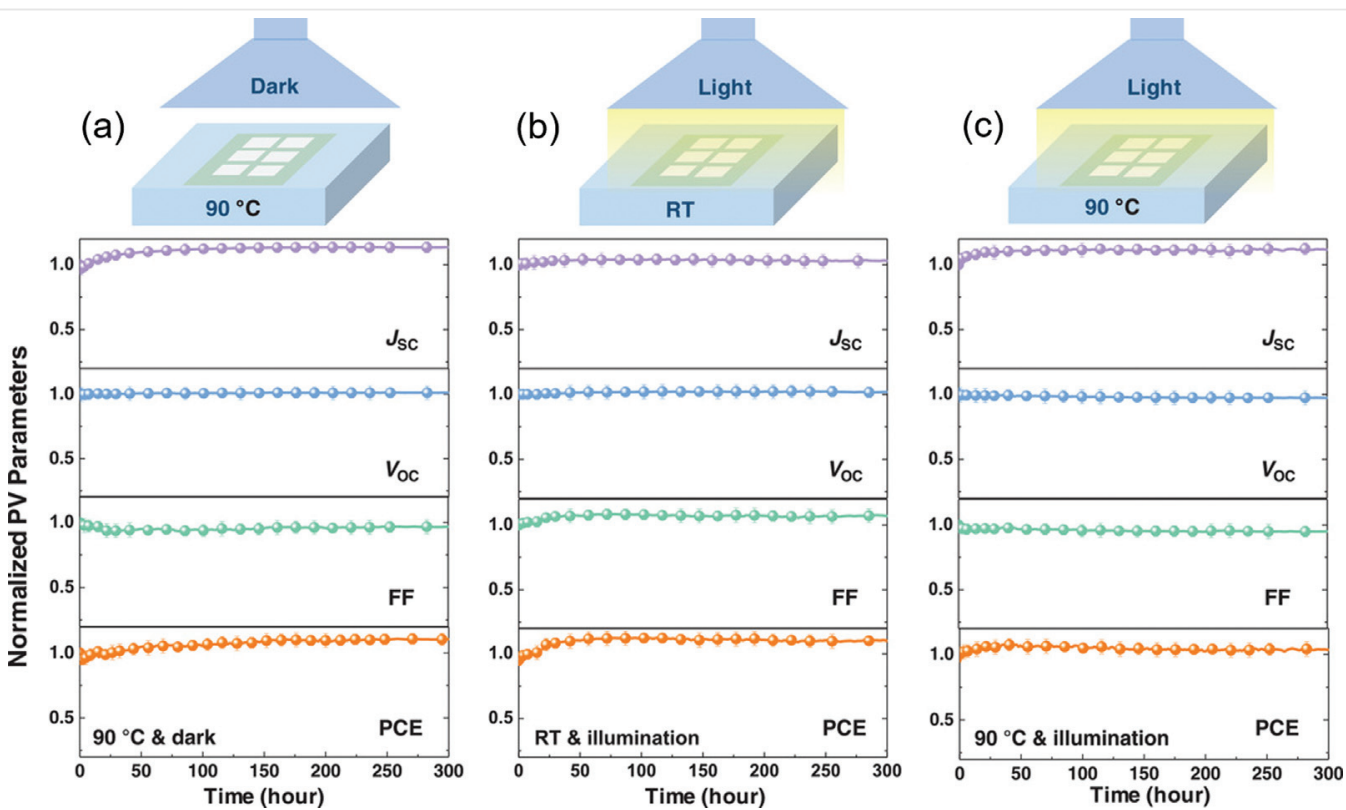

Figure 10 Stability test of double-cable polymer P7-based SCOSCs: (a) thermal stability at $90^{\circ} \mathrm{C}$ in the dark, (b) illumination stability with AM $1.5 \mathrm{G}$ LED light source at room temperature, (c) at $90{ }^{\circ} \mathrm{C}$ and AM 1.5G LED illumination condition. Reproduced with permission from Ref. ${ }^{110}$. Copyright 2019 John Wiley and sons.

provides the necessary flexibility for such sub-nm rearrangements. Despite small, the relative orientation of the molecules to each other governs the orbital overlap and the corresponding charge transfer integral between the single moieties, which are representative for charge generation, charge transport and charge recombination. The thermal stability of these three dyads was tested in the device architecture ITO/ZnO/active layer/ $/ \mathrm{MoO}_{x} / \mathrm{Ag}$ at $90{ }^{\circ} \mathrm{C}$ in the dark in a nitrogen atmosphere for over $300 \mathrm{~h}$. Interestingly, the dyads showed a distinctly different behavior as shown in Figure $9 \mathrm{~b} .{ }^{62}$ M11a $(\mathrm{PCE}=4.21 \%)$ with the shortest linker exhibited the highest thermal stability with $90 \%$ of the initial efficiency left, while M11c $(\mathrm{PCE}=3.34 \%$ ) with the longest linker showed the worst stability with only $60 \%$ efficiency left. Although interface-related degradation cannot be completely ruled out, molecular rearrangement appears more obviously for dyads with longer spacers. This highlights the need for further in-depth studies on the dual importance of spacer length for performance and stability. Given the enormously robust nanostructure of SCOSC materials, one would expect to see devices which do not show any degradation at all under thermal stress.

The question on the limits of thermal stability was as well triggered by the high temperatures found for posttreatment. Active layer post-treatments at temperatures of around $200^{\circ} \mathrm{C}$ do raise the question on the ultimate thermal stability of SCOSCs. ${ }^{110}$ As reported in 2019, a double-cable polymer (P7) using a DPP-based backbone and pendant PBI with a PCE of 2.74\% required a post treatment of the active layer at $200{ }^{\circ} \mathrm{C}$ for $10 \mathrm{~min}$ to gain full performance. ${ }^{110} \mathrm{As}$ depicted in Figure 10a, we found no signs of degradation for P7-based SCOSCs at $90{ }^{\circ} \mathrm{C}$ in the dark during a $300 \mathrm{~h}$ test period. In addition, surprisingly, when increasing the temperature from $25{ }^{\circ} \mathrm{C}$ to $150{ }^{\circ} \mathrm{C}$, the efficiency of P7based SCOSCs displayed a temperature coefficient comparable to Si or GaAs solar cells. When further increasing the temperature, the performance of SCP3-based SCOSCs remained stable until at around $160{ }^{\circ} \mathrm{C}$ and then started to slightly decrease at $200{ }^{\circ} \mathrm{C}$ because of the penetration of the Ag electrode. ${ }^{10}$ Such exceptional thermal stability is not unique in P7-based SCOSCs. Recently, we investigated further SCOSCs with PCE above 6\% and found excellent thermal stability at $90{ }^{\circ} \mathrm{C} .{ }^{111}$ It is important to stress that these systems showed no changes for a period of over $1000 \mathrm{~h}$ and thus do meet the thermal stability criteria of the IEC tests for photovoltaics. However, we want to emphasize that such exceptional stability was actually expected given the high annealing temperatures. Annealing temperatures above $200^{\circ} \mathrm{C}$ (i.e. above the glass transition temperatures of the side chains and probably as well the polymeric backbone) are plausible to create microstructure arrangements which are in thermodynamic equilibrium after cooling down. Such high temperature annealing treatments as a function of time might therefore be a smart method to quickly reveal whether a material is capable of forming a thermally stable morphology and should be regularly performed for $\mathrm{BHJ}$ composites as well. 


\section{Illumination Stability}

SCOSCs were highly spoken with respect to their excellent thermal stability. Nevertheless, their illumination stability has not been investigated until very recently. In 2020, Kwon et al. reported a di-block copolymer P16 (chemical structure shown in Figure 6) with an efficiency of 6.22\% under 1 sun illumination. ${ }^{87} \mathbf{P 1 6}$ was measured under atmospheric indoor conditions without encapsulation under LED lighting (@500 lux), and after 110 minutes of light irradiation, as shown in Figure 11a and b, the PCE of the P16-based SCOSCs showed almost negligible reduction $(\sim 1 \%)$, while that of the blend film-based OSCs was reduced to $85 \%$ of the initial PCE. ${ }^{87}$

Despite a slight burn-in degradation of D-A small molecule M11a under thermal aging tests at $90{ }^{\circ} \mathrm{C}$, we tested the operational stability of M11a under 1 sun equivalent and mild temperatures. M11a-based SCOSCs showed exceptional illumination stability without burn-in under LED light (400-800 nm) with $100 \mathrm{~mW} \mathrm{~cm}^{-2}$ intensity at room temperature, as shown in Figure $11 c{ }^{62}$ We recently showed that both light and temperature can cause similar microstructure degradation patterns, whereas temperatures of 65 or $85^{\circ} \mathrm{C}$ could cause significantly faster (up to an order or more) burn-in degradation than illumination under 1 sun. ${ }^{112}$ Having seen that it takes $300 \mathrm{~h}$ and $90{ }^{\circ} \mathrm{C}$ to cause a burn-in loss of $10 \%$, it is actually not too surprising to observe no degradation under 1 sun at room temperature for $1000 \mathrm{~h}{ }^{62}$ Nevertheless, we want to highlight that only few OSCs were reported to show a flat performance trend

(a)

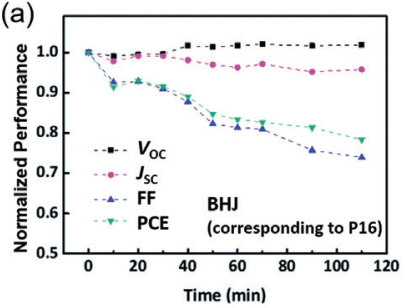

(c)
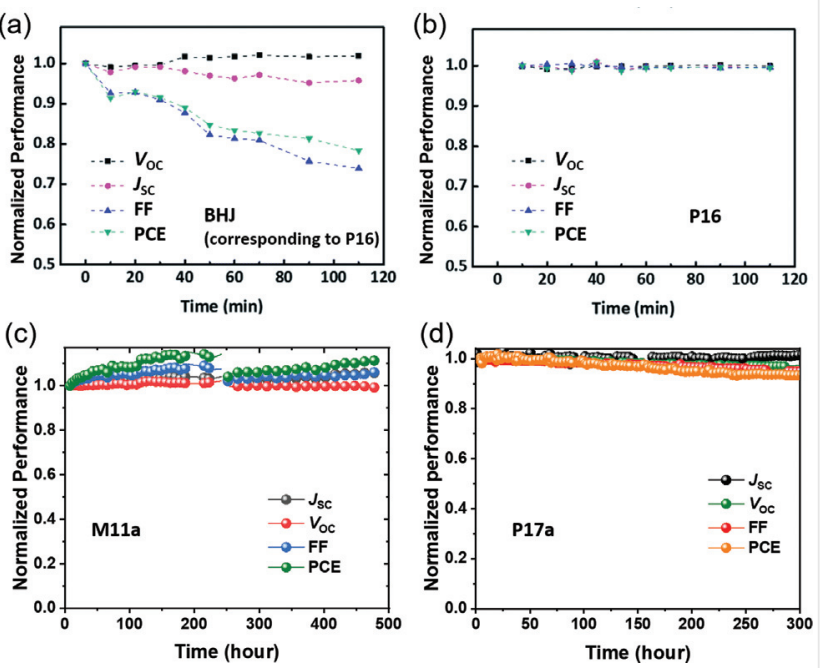

Figure 11 Illumination stability: (a) BHJ solar cells corresponding to P16; (b) P16-based SCOSCs under an LED lamp (@500 lux). Reproduced with permission from Ref. ${ }^{87}$. Copyright 2020 Royal Society of Chemistry. Illumination stability under LED light (AM $1.5 \mathrm{G}$ condition) of (c) M11a-based ${ }^{62}$ and (d) P17a-based SCOSCs. Reproduced with permission from Ref. ${ }^{39}$. Copyright 2019 Elsevier. for $1000 \mathrm{~h}$ at 1 equivalent sun testing. We found similar but not identical trends for P17a (Figure 11d), which started with an efficiency of over $6 \%$. After $300 \mathrm{~h}$ under LED illumination in a nitrogen atmosphere, 93\% of initial PCE was retained. ${ }^{39}$ As the degradation pattern for P17a is atypical for burn-in degradation, interface or bulk photostability effects need to be investigated in more detail.

To further gain insight into the temperature and illumination stability, we have performed a systematic study on the stability of SCOSCs based on P7, as shown in Figure $10 .{ }^{110}$ Stability tests were conducted in a nitrogen atmosphere for $300 \mathrm{~h}$ under multiple conditions: $90{ }^{\circ} \mathrm{C}$ and dark, room temperature and illumination, $90{ }^{\circ} \mathrm{C}$ and illumination. It is surprising that none of these conditions could initiate degradation of the photovoltaic performance of P7-based SCOSCs. Encouragingly, under rugged operation conditions ( $90{ }^{\circ} \mathrm{C}$ and illumination), P7-based SCOSCs still exhibited excellent stability without efficiency decrease during the $300 \mathrm{~h}$ aging test. ${ }^{110}$

SCOSCs are inherently attractive for industrial applications where one prefers simple and reproducible processing without constantly worrying about ink formulation, batch variations or phase segregation. However, SCOSCs are still at their primary stage of development and a more advanced investigation on their degradation processes is lacking. Currently, the relation between stability behavior and the material structure (polymer-based or small moleculebased) is unclear with respect to the contributions from bulk effects versus interface effects during thermal and/or illumination stress. The conclusion that all the SCOSCs are absolutely stable could not be drawn. Nevertheless, single SCOSCs have shown initial excellent stability behavior when compared with other OSCs (PHJ and $\mathrm{BHJ}$ ), beneficial from the suppressed macrophase separation by the space linker connected D-A structure. If degradation behavior exists in SCOSCs, it cannot be caused by the large-scale phase separation or the aggregation effect of donor or acceptor, since only localized molecular vibration and rotation are allowed due to the restriction of linker and the spatial hindrance. From the dependence of thermal stability on the length of space linker in M11, it is clear that degradation does exist for some SCOSCs. This phenomenon is probably caused by their relatively low glass transition $\left(T_{\mathrm{g}}\right)$ temperature and melting point, and the resultant higher freedom of molecular movement and rearrangement. In the case of double-cable polymers with high $T_{\mathrm{g}}$, their thermal stability would be definitely excellent, similar to the discovery in $\mathrm{BHJ}$ systems. Thermal stability is relatively easy to analyze, which is mainly related to the freedom of chain movement and the possibility of morphology rearrangement. On the other hand, the illumination stability of some reported SCOSCs is also impressively high, and some SCOSCs even exhibit no degradation during the light soaking test. The photo-induced formation of radicals in SCOSCs has not been 
investigated yet, and, it would be interesting to study these fundamental processes in such model systems as compared to $\mathrm{BHJ}$ composites. For the most stable active materials employed in SCOSCs, ultimate stability could be researched under extreme and rugged conditions, such as ultra-high temperature and/or concentrated light illumination. Besides, thanks to the absence of active-layer phase separation, these materials can be used as reference materials for organic photovoltaics in general, as ultimate candidates to differentiate between surface losses and bulk losses as well as unique materials to identify interface-related degradation versus bulk degradation.

\section{Conclusions and Outlook}

This mini-review summarizes the research progress of SCOSCs, focusing on their photovoltaic performance development and stability. Compared with BHJ solar cells, SCOSCs are still in their infancy. The diversified structures of materials applied in SCOSCs will stimulate more research. In future research, the following aspects of SCOSCs need to be understood in more scientific depth in order to acquire even higher-efficiency SCOSCs.

First of all, the design of new materials for SCOSCs requires improved understanding of how to align and optimize the donor, acceptor and spacer units at the same time. Suitable donor units could be identified by learning from high-performance BHJ donor material concepts, especially from the current generation of electron-donating-electron-withdrawing low-bandgap compounds. The acceptor unit could be based on state-of-the-art highperformance NFA materials. One might as well identify suitable compounds by learning from $\mathrm{BHJ}$ composites. $\mathrm{BHJ}$ composites which are stable under elevated annealing temperatures for long periods indicate that these two compounds are capable of forming thermodynamically stable structures. Following that philosophy, such composites might be converted into single-component semiconductors by identifying the right length of the linker. Through such strategy, future materials for SCOSCs with different absorption, energy levels, crystallinity and mobility could be obtained, which provide a basis for studying the relationship between structure and performance.

Second, our understanding and control on the processes governing nanophase separation in SCOSC materials needs to be further improved. The nanophase morphology of donor and acceptor parts is tightly related to the exciton diffusion and charge transporting processes. The morphology research can be carried out under the following aspects: (i) constructing continuous electron and hole transport channels to reduce recombination. The charge carrier mobility for holes and electrons should be further improved and at the same time balanced. Realizing highly ordered stacking of acceptor side chains is an important issue for improving the performance of SCOSCs. (ii) Developing the methods to characterize the nanophase-separated molecular motifs in SCOSCs. The micro-morphology of the active material in SCOSCs includes crystalline regions, random regions and contact interfaces. Compared with traditional $\mathrm{BHJ}$ systems, the morphology research of SCOSC materials is happening on a molecular scale with sub-nm dimensions and will require the development of novel methods. In terms of analysis, various characterization methods could be envisaged to give improved insight into the nano-phase separation kinetics between the donor and the acceptor, such as temperature-dependent in-situ Raman and photoluminescence spectroscopy or even in-situ X-Ray and neutron scattering experiments. (iii) Having learned that molecular dyads or double-cable polymers will not undergo large-scale microstructure rearrangements, multiscale simulation appears as a feasible method to ab-initio model and even design suitable composites. With more systematic studies and materials coming along, even artificial intelligence-supported material design comes within reach. Gaussian process regression can work with rather small datasets of 100 or 100 s of samples. A number which we easily may see in the next few years.

Third, studying the photo-physical process in SCOSCs to obtain the general relation between structure and performance of SCOSCs. Compared with the BHJ systems, SCOSCs have a smaller phase separation size for the donor and the acceptor, which might lead to distinctly different photogeneration processes or carrier recombination processes. The likely occurrence of more prominent non-geminate recombination must be investigated in more detail. For example, as one can exclude charge generation from the backbone to the associated side chain within one molecule, it is important to understand at which locations precisely excitons are split. Another open question is the exciton diffusion length in these excitingly novel materials. The current knowledge about the photo-physics of SCOSCs is limited and requires extensive research on different types of materials related.

Fourth, investigating the degradation mechanism of SCOSCs is of major interest. With the rapid efficiency development of SCOSCs to $8.4 \%$, this field is getting closer to as well gain industrial interest. Despite the conceptual better morphological stability, SCOSCs present different degradation patterns for the single material concepts. Once this is better understood, SCOSCs can offer improved understanding by acting as model systems for isolated degradation mechanisms. For instance, once microstructure modifications can be excluded as a possible source of degradation, such materials are ideal candidates to selectively study interface degradation. Thermal stability, illumination stability and shelf stability can be studied with respect to bulk vs. interface failure. Even more 
interesting will be the question of photo-oxidation. Isolated radicals on electron acceptor sites are suspected as a source for the formation of oxygen radicals. It will be important to understand whether such isolated and long lived radicals do exist in SCOSCs. In addition to all the benefits of improved stability, we foresee that outstandingly stable SCOSCs will become model systems to investigate an isolated degradation process as for instance surface recombination of interface-induced degradation.

SCOSCs are an excitingly thrilling topic, and with the joint efforts from chemists, physicists and engineers, SCOSCs will see a prospective renaissance in the near future with efficiency values of over $10 \%$, significantly enhanced reproducibility and reliable operational lifetime behavior as required for industrial applications.

\section{Funding Information}

Y.H. is grateful to the financial support from China Scholarship Council (CSC) and Erlangen Graduate School in Advanced Optical Technologies (SAOT). C.J.B. gratefully acknowledges funding by the Deutsche Forschungsgemeinschaft (DFG, German Research Foundation) under the project numbers 182849149-SFB 953 and INST 90/917, INST 90/1093-1, financial support through the "Aufbruch Bayern" initiative of the state of Bavaria (EnCN and SFF) and the Bavarian Initiative "Solar Technologies go Hybrid" (SolTech) and the grant "ELF-PV Design and Development of Solution Processed Functional Materials for the Next Generations of PV Technologies" by the Bavarian State Government (No. 44-6521a/20/4).

\section{References}

(1) Li, H.; Xiao, Z.; Ding, L.; Wang, J. Sci. Bull. 2018, 63, 340.

(2) Zhang, S.; Qin, Y.; Zhu, J.; Hou, J. Adv. Mater. 2018, 30, 1800868.

(3) Koster, L. J. A.; Shaheen, S. E.; Hummelen, J. C. Adv. Energy Mater. 2012, 2, 1246.

(4) Donaghey, J. E.; Armin, A.; Burn, P. L.; Meredith, P. Chem. Commun. 2015, 51, 14115.

(5) Halls, J. J. M.; Walsh, C. A.; Greenham, N. C.; Marseglia, E. A.; Friend, R. H.; Moratti, S. C.; Holmes, A. B. Nature 1995, 376, 498.

(6) Yu, G.; Gao, J.; Hummelen, J. C.; Wudl, F.; Heeger, A. J. Science 1995, 270, 1789

(7) Sariciftci, N. S.; Smilowitz, L.; Heeger, A. J.; Wudl, F. Science 1992, 258, 1474

(8) Brabec, C. J.; Gowrisanker, S.; Halls, J. J. M.; Laird, D.; Jia, S.; Williams, S. P. Adv. Mater. 2010, 22, 3839.

(9) Wöhrle, D.; Meissner, D. Adv. Mater. 1991, 3, 129.

(10) Nakano, K.; Tajima, K. Adv. Mater. 2017, 29, 1603269.

(11) Roncali, J.; Grosu, I. Adv. Sci. 2019, 6, 1801026.

(12) Huang, Y.; Kramer, E. J.; Heeger, A. J.; Bazan, G. C. Chem. Rev. 2014, 114, 7006

(13) Junwu, C. A.; Yong, C. Acc. Chem. Res. 2009, 42, 1709.
(14) Roquet, S.; Cravino, A.; Leriche, P.; Alévêque, O.; Frère, P.; Roncali, J. J. Am. Chem. Soc. 2006, 128, 3459.

(15) Lloyd, M. T.; Anthony, J. E.; Malliaras, G. G. Mater. Today 2007, $10,34$.

(16) Günes, S.; Neugebauer, H.; Sariciftci, N. S. Chem. Rev. 2007, 107, 1324.

(17) Yang, X.; Loos, J.; Veenstra, S. C.; Verhees, W. J. H.; Wienk, M. M.; Kroon,J. M.; Michels, M. A.J.; Janssen, R. A.J. Nano Lett. 2005, 5, 579 .

(18) Roncali, J. Macromol. Rapid Commun. 2007, 28, 1761.

(19) Cheng, Y. J.; Yang, S. H.; Hsu, C. S. Chem. Rev. 2009, 109, 5868.

(20) Roquet, S.; De Bettignies, R.; Leriche, P.; Cravino, A.; Roncali, J.J. Mater. Chem. 2006, 16, 3040.

(21) Zhan, L.; Li, S.; Lau, T. K.; Cui, Y.; Lu, X.; Shi, M.; Li, C. Z.; Li, H.; Hou, J.; Chen, H. Energy Environ. Sci. 2020, 13, 635.

(22) Wadsworth, A.; Moser, M.; Marks, A.; Little, M. S.; Gasparini, N.; Brabec, C. J.; Baran, D.; McCulloch, I. Chem. Soc. Rev. 2019, 48, 1596.

(23) Zhang, G.; Zhao, J.; Chow, P. C. Y.; Jiang, K.; Zhang, J.; Zhu, Z.; Zhang, J.; Huang, F.; Yan, H. Chem. Rev. 2018, 118, 3447.

(24) Zhao, W.; Qian, D.; Zhang, S.; Li, S.; Inganäs, O.; Gao, F.; Hou, J. Adv. Mater. 2016, 28, 4734.

(25) Eftaiha, A. F.; Sun, J. P.; Hill, I. G.; Welch, G. C. J. Mater. Chem. A 2014, 2, 1201.

(26) Lin, Y.; Wang, J.; Zhang, Z. G.; Bai, H.; Li, Y.; Zhu, D.; Zhan, X. Adv. Mater. 2015, 27, 1170.

(27) Bai, H.; Wang, Y.; Cheng, P.; Wang, J.; Wu, Y.; Hou, J.; Zhan, X. J. Mater. Chem. A 2015, 3, 1910.

(28) Li, M.; Liu, Y.; Ni, W.; Liu, F.; Feng, H.; Zhang, Y.; Liu, T.; Zhang, H.; Wan, X.; Kan, B.; Zhang, Q.; Russell, T. P.; Chen, Y. J. Mater. Chem. A 2016, 4, 10409.

(29) Cui, C.; Guo, X.; Min, J.; Guo, B.; Cheng, X.; Zhang, M.; Brabec, C. J.; Li, Y. Adv. Mater. 2015, 27, 7469.

(30) Brabec, C. J.; Distler, A.; Du, X.; Egelhaaf, H. J.; Hauch, J.; Heumueller, T.; Li, N. Adv. Energy Mater. 2020, 10, 2001864.

(31) Cheng, P.; Zhan, X. Chem. Soc. Rev. 2016, 45, 2544.

(32) Duan, L.; Uddin, A. Adv. Sci. 2020, 7, 1903259.

(33) Heumueller, T.; Mateker, W. R.; Sachs-Quintana, I. T.; Vandewal, K.; Bartelt, J. A.; Burke, T. M.; Ameri, T.; Brabec, C. J.; McGehee, M. D. Energy Environ. Sci. 2014, 7, 2974.

(34) Fraga Domínguez, I.; Distler, A.; Lüer, L. Adv. Energy Mater. 2017, 7, 1601320.

(35) Mateker, W. R.; McGehee, M. D. Adv. Mater. 2017, 29, 1603940.

(36) Roncali, J. Adv. Energy Mater. 2011, 1, 147.

(37) Wang, W.; Sun, R.; Guo, J.; Guo, J.; Min, J. Angew. Chem. Int. Ed. 2019, 58, 14556.

(38) Li, C.; Wu, X.; Sui, X.; Wu, H.; Wang, C.; Feng, G.; Wu, Y.; Liu, F.; Liu, X.; Tang, Z.; Li, W. Angew. Chem. 2019, 131, 15678.

(39) Feng, G.; Li, J.; He, Y.; Zheng, W.; Wang, J.; Li, C.; Tang, Z.; Osvet, A.; Li, N.; Brabec, C. J.; Yi, Y.; Yan, H.; Li, W. Joule 2019, 3, 1765.

(40) Lin, Y.; Li, Y.; Zhan, X. Chem. Soc. Rev. 2012, 41, 4245.

(41) Roncalia, J. Chem. Soc. Rev. 2005, 34, 483.

(42) Segura, J. L.; Martín, N.; Guldi, D. M. Chem. Soc. Rev. 2005, 34, 31.

(43) Martín, N.; Sánchez, L.; Illescas, B.; Pérez, I. Chem. Rev. 1998, 98, 2527.

(44) Ramos, A. M.; Rispens, M. T.; van Duren, J. K. J.; Hummelen, J. C.; Janssen, R. A. J. J. Am. Chem. Soc. 2001, 123, 6714.

(45) Zhang, F.; Svensson, M.; Andersson, M. R.; Maggini, M.; Bucella, S.; Menna, E.; Inganäs, O. Adv. Mater. 2001, 13, 1871.

(46) Mitchell, V. D.; Jones, D. J. Polym. Chem. 2018, 9, 795.

(47) Robb, M. J.; Ku, S.-Y.; Hawker, C. J. Adv. Mater. 2013, 25, 5686. 
(48) Liu, H.; Gao, H.; Lin, J.; Hayat, T.; Alsaedi, A.; Tan, Z. Sustainable Energy Fuels 2020, 4, 3190.

(49) Chamberlain, G. A.; Cooney, P. J. Chem. Phys. Lett. 1979, 66, 88.

(50) Kallmann, H.; Pope, M. J. Chem. Phys. 1959, 30, 585.

(51) Chamberlain, G. A.; Cooney, P.J.; Dennison, S. Nature 1981,289, 45.

(52) Yamamoto, S.; Yasuda, H.; Ohkita, H.; Benten, H.; Ito, S.; Miyanishi, S.; Tajima, K.; Hashimoto, K. J. Phys. Chem. C 2014, $118,10584$.

(53) Yu, C.; Xu, Y.; Li, C.; Feng, G.; Yang, F.; Li, J.; Li, W. Chin. J. Chem. 2018, 36, 515.

(54) Hu, Z.; Wang, J.; Wang, Z.; Gao, W.; An, Q.; Zhang, M.; Ma, X.; Wang, J.; Miao, J.; Yang, C.; Zhang, F. Nano Energy 2019, 55, 424.

(55) Wang, J.-L.; Liu, K.-K.; Liu, S.; Xiao, F.; Chang, Z.-F.; Zheng, Y.-Q.; Dou, J.-H.; Zhang, R.-B.; Wu, H.-B.; Pei, J.; Cao, Y. Chem. Mater. 2017, 29, 1036.

(56) Yang, F.; Li, C.; Lai, W.; Zhang, A.; Huang, H.; Li, W. Mater. Chem. Front. 2017, 1, 1389.

(57) Jiang, X.; Yang, J.; Karuthedath, S.; Li, J.; Lai, W.; Li, C.; Xiao, C.; Ye, L.; Ma, Z.; Tang, Z.; Laquai, F.; Li, W. Angew. Chem. 2020, 132, 21867.

(58) Ku, S. Y.; Brady, M. A.; Treat, N. D.; Cochran, J. E.; Robb, M. J.; Kramer, E. J.; Chabinyc, M. L.; Hawker, C. J. J. Am. Chem. Soc. 2012, 134, 16040.

(59) Wang, J.; Ueda, M.; Higashihara, T. ACS Macro Lett. 2013, 2, 506.

(60) Park, S. H.; Kim, Y.; Kwon, N. Y.; Lee, Y. W.; Woo, H. Y.; Chae, W.; Park, S.; Cho, M. J.; Choi, D. H. Adv. Sci. 2020, 7, 1902470.

(61) Liu, X.; Xie, B.; Duan, C.; Wang, Z.; Fan, B.; Zhang, K.; Lin, B.; Colberts, F. J. M.; Ma, W.; Janssen, R. A. J.; Huang, F.; Cao, Y. J. Mater. Chem. A 2018, 6, 395.

(62) Lucas, S.; Kammerer, J.; Pfannmöller, M.; Schröder, R. R.; He, Y.; Li, N.; Brabec, C. J.; Leydecker, T.; Samorì, P.; Marszalek, T.; Pisula, W.; Mena-Osteritz, E.; Bäuerle, P. Sol. RRL 2021, 5, 2000653.

(63) Labrunie, A.; Habibi, A. H.; Dabos-Seignon, S.; Blanchard, P.; Cabanetos, C. Dyes Pigm. 2019, 170, 107632.

(64) Zhang, Y.; Deng, D.; Wu, Q.; Mi, Y.; Yang, C.; Zhang, X.; Yang, Y.; Zou, W.; Zhang, J.; Zhu, L.; Zhou, H.; Liu, X.; Wei, Z. Sol. RRL 2020, 4, 1900580.

(65) Mannanov, A. L.; Savchenko, P. S.; Luponosov, Y. N.; Solodukhin, A. N.; Ponomarenko, S. A.; Paraschuk, D. Y. Org. Electron. 2020, $78,105588$.

(66) Nishizawa, T.; Lim, H. K.; Tajima, K.; Hashimoto, K. Chem. Commun. 2009, 18, 2469.

(67) Izawa, S.; Hashimoto, K.; Tajima, K. Phys. Chem. Chem. Phys. 2012, 14, 16138.

(68) Nguyen, T. L.; Lee, T. H.; Gautam, B.; Park, S. Y.; Gundogdu, K.; Kim, J. Y.; Woo, H. Y. Adv. Funct. Mater. 2017, 27, 1702474.

(69) Narayanaswamy, K.; Venkateswararao, A.; Nagarjuna, P.; Bishnoi, S.; Gupta, V.; Chand, S.; Singh, S. P. Angew. Chem. Int. Ed. 2016, 55, 12334.

(70) Bu, L.; Guo, X.; Yu, B.; Fu, Y.; Qu, Y.; Xie, Z.; Yan, D.; Geng, Y.; Wang, F. Polymer 2011, 52, 4253.

(71) Xia, D.; Yang, F.; Li, J.; Li, C.; Li, W. Mater. Chem. Front. 2019, 3, 1565.

(72) Qu, J.; Gao, B.; Tian, H.; Zhang, X.; Wang, Y.; Xie, Z.; Wang, H.; Geng, Y.; Wang, F. J. Mater. Chem. A 2014, 2, 3632.

(73) Lindner, S. M.; Hüttner, S.; Chiche, A.; Thelakkat, M.; Krausch, G. Angew. Chem. Int. Ed. 2006, 45, 3364.

(74) Lee, D. H.; Lee, J. H.; Kim, H. J.; Choi, S.; Park, G. E.; Cho, M. J.; Choi, D. H. J. Mater. Chem. A 2017, 5, 9745.
(75) Liang, S.; Xu, Y.; Jiang, X.; Li, C.; Li, W. Dyes Pigm. 2019, 170 , 107575.

(76) Liang, S.; Xu, Y.; Li, C.; Li, J.; Wang, D.; Li, W. Polym. Chem. 2019, $10,4584$.

(77) Yang, F.; Wang, X.; Feng, G.; Ma, J.; Li, C.; Li, J.; Ma, W.; Li, W. Sci. China Chem. 2018, 61, 824.

(78) Chen, P.; Nakano, K.; Suzuki, K.; Hashimoto, K.; Kikitsu, T.; Hashizume, D.; Koganezawa, T.; Tajima, K. ACS Appl. Mater. Interfaces 2017, 9, 4758.

(79) Lai, W.; Li, C.; Zhang, J.; Yang, F.; Colberts, F. J. M.; Guo, B.; Wang, Q. M.; Li, M.; Zhang, A.; Janssen, R. A. J.; Zhang, M.; Li, W. Chem. Mater. 2017, 29, 7073.

(80) Guo, C.; Lin, Y. H.; Witman, M. D.; Smith, K. A.; Wang, C.; Hexemer, A.; Strzalka, J.; Gomez, E. D.; Verduzco, R. Nano Lett. 2013, 13, 2957.

(81) Lee, J. H.; Park, C. G.; Kim, A.; Kim, H. J.; Kim, Y.; Park, S.; Cho, M. J.; Choi, D. H. ACS Appl. Mater. Interfaces 2018, 10, 18974.

(82) Feng, G.; Li, J.; Colberts, F. J. M.; Li, M.; Zhang, J.; Yang, F.; Jin, Y.; Zhang, F.; Janssen, R. A. J.; Li, C.; Li, W. J. Am. Chem. Soc. 2017, 139, 18647.

(83) Yang, F.; Li, J.; Li, C.; Li, W. Macromolecules 2019, 52, 3689.

(84) Lanzi, M.; Pierini, F. ACS Omega 2019, 4, 19863.

(85) Pierini, F.; Lanzi, M.; Nakielski, P.; Pawlowska, S.; Urbanek, O.; Zembrzycki, K.; Kowalewski, T. A. Macromolecules 2017, 50, 4972.

(86) Lanzi, M.; Salatelli, E.; Marinelli, M.; Pierini, F. Macromol. Chem. Phys. 2020, 221, 1900433.

(87) Kwon, N. Y.; Park, S. H.; Kang, H.; Takaloo, A. V.; Harit, A. K.; Woo, H. Y.; Kim, T. G.; Yoon, H. J.; Cho, M. J.; Choi, D. H. J. Mater. Chem. A 2020, 8, 20091.

(88) Yu, P.; Feng, G.; Li, J.; Li, C.; Xu, Y.; Xiao, C.; Li, W. J. Mater. Chem. C 2020, 8, 2790.

(89) Labrunie, A.; Gorenflot, J.; Babics, M.; Alévêque, O.; DabosSeignon, S.; Balawi, A. H.; Kan, Z.; Wohlfahrt, M.; Levillain, E.; Hudhomme, P.; Beaujuge, P. M.; Laquai, F.; Cabanetos, C.; Blanchard, P. Chem. Mater. 2018, 30, 3474.

(90) Labrunie, A.; Lebailly, T.; Habibi, A. H.; Dalinot, C.; Jiang, Y.; Dabos-Seignon, S.; Roncali, J.; Blanchard, P.; Cabanetos, C. Metals 2019, 9, 618.

(91) Wang, T.; Sun, H.; Zhang, L.; Colley, N. D.; Bridgmohan, C. N.; Liu, D.; Hu, W.; Li, W.; Zhou, X.; Wang, L. Dyes Pigm. 2017, 139, 601.

(92) Izawa, S.; Hashimoto, K.; Tajima, K. Chem. Commun. 2011, 47, 6365.

(93) Bu, L.; Guo, X.; Yu, B.; Qu, Y.; Xie, Z.; Yan, D.; Geng, Y.; Wang, F. J. Am. Chem. Soc. 2009, 131, 13242.

(94) Lucas, S.; Leydecker, T.; Samorì, P.; Mena-Osteritz, E.; Bäuerle, P. Chem. Commun. 2019, 55, 14202.

(95) Tan, Z.; Hou, J.; He, Y.; Zhou, E.; Yang, C.; Li, Y. Macromolecules 2007, 40, 1868.

(96) Zhang, Q.; Cirpan, A.; Russell, T. P.; Emrick, T. Macromolecules 2009, 42, 1079.

(97) Marinelli, M.; Lanzi, M.; Liscio, A.; Zanelli, A.; Zangoli, M.; Di Maria, F.; Salatelli, E. J. Mater. Chem. C 2020, 8, 4124.

(98) Koyuncu, S.; Wang, H. W.; Liu, F.; Toga, K. B.; Gu, W.; Russell, T. P. J. Mater. Chem. A 2014, 2, 2993.

(99) Lombeck, F.; Komber, H.; Sepe, A.; Friend, R. H.; Sommer, M. Macromolecules 2015, 48, 7851.

(100) Wang, S.; Yang, Q.; Tao, Y.; Guo, Y.; Yang, J.; Liu, Y.; Zhao, L.; Xie, Z.; Huang, W. New J. Chem. 2016, 40, 1825.

(101) Miyanishi, S.; Zhang, Y.; Tajima, K.; Hashimoto, K. Chem. Commun. 2010, 46, 6723. 
(102) Lee, Y.; Aplan, M. P.; Seibers, Z. D.; Kilbey, S. M.; Wang, Q.; Gomez, E. D. J. Mater. Chem. A 2017, 5, 20412.

(103) Mok, J. W.; Lin, Y.-H.; Yager, K. G.; Mohite, A. D.; Nie, W.; Darling, S. B.; Lee, Y.; Gomez, E.; Gosztola, D.; Schaller, R. D.; Verduzco, R. Adv. Funct. Mater. 2015, 25, 5578.

(104) Miyanishi, S.; Zhang, Y.; Hashimoto, K.; Tajima, K. Macromolecules 2012, 45, 6424

(105) Lee, Y.; Aplan, M. P.; Seibers, Z. D.; Xie, R.; Culp, T. E.; Wang, C.; Hexemer, A.; Kilbey, S. M.; Wang, Q.; Gomez, E. D. Macromolecules 2018, 51, 8844.

(106) Raissi, M.; Erothu, H.; Ibarboure, E.; Bejbouji, H.; Cramail, H.; Cloutet, E.; Vignau, L.; Hiorns, R. C.J. Mater. Chem. A 2017, 5, 7533.

(107) Baran, D.; Gasparini, N.; Wadsworth, A.; Tan, C. H.; Wehbe, N.; Song, X.; Hamid, Z.; Zhang, W.; Neophytou, M.; Kirchartz, T.;
Brabec, C. J.; Durrant, J. R.; McCulloch, I. Nat. Commun. 2018 $9,1$.

(108) Bartesaghi, D.; Pérez, I. C.; Kniepert, J.; Roland, S.; Turbiez, M.; Neher, D.; Koster, L. J. A. Nat. Commun. 2015, 6, 7083.

(109) Elumalai, N. K.; Saha, A.; Vijila, C.; Jose, R.; Jie, Z.; Ramakrishna, S. Phys. Chem. Chem. Phys. 2013, 15, 6831.

(110) He, Y.; Heumüller, T.; Lai, W.; Feng, G.; Classen, A.; Du, X.; Liu, C.; Li, W.; Li, N.; Brabec, C. J. Adv. Energy Mater. 2019, 9, 1900409.

(111) He, Y. et al., in preparation.

(112) Zhang, C.; Heumueller, T.; Leon, S.; Gruber, W.; Burlafinger, K.; Tang, X.; Perea, J. D.; Wabra, I.; Hirsch, A.; Unruh, T.; Li, N.; Brabec, C. J. Energy Environ. Sci. 2019, 12, 1078. 